\title{
Configurando el modelo social de la Europa post-Brexit: perspectivas y acciones en curso ${ }^{1}$
}

\author{
Shaping the Social Model of the Post-Brexit Europe: \\ Perspectives and Ongoing Actions
}

\author{
Ainhoa Lasa López \\ Profesora Doctora de Derecho Constitucional \\ Universidad de Alicante \\ ainhoa.lasa@ua.es
}

Sumario: I. ¿Qué Europa social? La encrucijada de la integración positiva: regulación indirecta nominal, convergencia social al alza o intervención directa. - II. Paquete de movilidad laboral 2016: Un mercado interior más justo y más profundo con una base industrial fortalecida 1 . Propuesta de Directiva del Parlamento Europeo y del Consejo que modifica la Directiva 96/71/CE del Parlamento Europeo y del Consejo, de 16 de diciembre de 1996, sobre el desplazamiento de trabajadores efectuado en el marco de una prestación de servicios. 1.1. Directiva (UE) 2018/957 del Parlamento Europeo y del Consejo de 28 de junio de 2018 que modifica la Directiva 96/71/CE sobre el desplazamiento de trabajadores efectuado en el marco de una prestación de servicios. 2. Propuesta de Reglamento del Parlamento Europeo y del Consejo por el que se modifican el Reglamento (CE) n.. 883/2004, sobre la coordinación de los sistemas de seguridad social, y el Reglamento (CE) n. ${ }^{\circ}$ 987/2009, por el que se adoptan las normas de aplicación del Reglamento (CE) n. ${ }^{\circ} 883 / 2004$. - III. Documento de reflexión sobre la dimensión social de Europa: minimalismo, descentralización, renacionalización o socialización del proyecto de integración. - IV El Pilar Europeo de Derechos Sociales: ¿isonomía de los objetivos sociales y las libertades económicas? $-\mathrm{V}$. El paquete de equidad social: contenidos propositivos.-VI. Conclusiones.-VII. Bibliografía.

Resumen: La dimensión social europea ha adquirido, al menos en el plano teórico político de los últimos tres años, una cierta autosuficiencia que

${ }^{1}$ El presente estudio se enmarca dentro del proyecto de investigación, Estado Económico, Capitalismo financiarizado, Constitución, Gobernanza (DER 2017-84562-P) financiado por el Ministerio de Economía y Competitividad, en el marco del Plan Estatal de Investigación Científica y Técnica de Innovación 2013-2016. 
parece alejarla de aquel escenario inmediato a la implosión de la crisis de la eurozona donde las declaraciones y propuestas para la vialidad del proyecto se circunscribían, sin ambages, a la supervivencia de la gobernanza económica europea. Empero, esta renaissance de la integración social en el discurso oficial no ha sido fruto de una variable estocástica, sino de una doble conjunción de factores: inicialmente, un guiño a las reiteradas demandas del Reino Unido de limitar las ayudas sociales a ciudadanía europea económicamente inactiva, con la finalidad de neutralizar, entonces, un hipotético triunfo del Brexit. En un momento posterior, para paliar los déficits democráticos de la Unión durante la gestión de la crisis cuyos efectos sociales en los Estados miembros han sido correlativos al peligroso incremento exponencial en los parlamentos nacionales de fuerzas políticas eurófobas. Unos enfoques tácticos, pragmáticos y programáticos presentes en los programas de trabajo de la Comisión Europea de 2016, 2017 y 2018, en los que la integración positiva continúa anclada a propuestas donde lo social es viable en los fines, pero no en los medios.

Palabras clave: economía social de mercado, derechos sociales condicionados, libertades económicas, regulación social indirecta, vínculo social.

Abstract: The European social dimension has acquired, at least on the theoretical political plane of the last four years, a certain self-sufficiency that seems to move it away from that immediate scenario to the implosion of the Eurozone crisis where the declarations and proposals for the project's viability circumscribed, without ambiguity, to the survival of European economic governance. However, this renaissance of social integration in the official discourse has not been the result of a stochastic variable, but of a double conjunction of factors: initially, a nod to the repeated demands of the United Kingdom to limit social aid to economically inactive European citizenship, with the aim of neutralizing, then, a hypothetical triumph of Brexit. At a later stage, to alleviate the Union's deficits during crisis management, the social effects of which in the Member States have been correlated with the dangerous exponential increase in national parliaments of Europhobic political forces. A tactical, pragmatic and programmatic approaches present in the European Commission's work programmes of 2016, 2017 and 2018, in which positive integration continues to be anchored in proposals where the social is viable in the ends, but not in the means.

Keywords: social market economy, conditional social rights, economic freedoms, indirect social regulation, social link. 


\section{I. ¿Qué Europa social? La encrucijada de la integración positiva: regulación indirecta nominal, convergencia social al alza o intervención directa}

La, hasta el momento parece que inevitable, consumación del Brexit ${ }^{2}$, unido a la cercanía de la convocatoria de elecciones al Parlamento Europeo (PE) que habrá de calibrarse con el avance imparable de formaciones parlamentarias y gobiernos de signo renacionalizador en los países miembros, anuncia para los próximos meses un escenario político jurídico en la Unión Europea (UE), cuanto menos, convulso. En paralelo, las principales instituciones de la Unión, con la Comisión al frente, trabajan, con mayor o menor acierto, para enmendar los efectos sistémicos del discurso hegemónico de la centralidad del mercado interior. En los estadios iniciales de la posible implosión de la eurozona, la garantía de la racionalidad del cálculo económico se convirtió en una proclama irrenunciable, aunque para ello debiera alterarse el tenor literal de las disposiciones del derecho originario, o recurrirse a mecanismos de derecho internacional que deslegitimaban los propios procesos decisorios supranacionales. La integración positiva, por el contrario, sonaba como una nota discordante en los memorándums de rescate y/o de entendimiento, y en la opacidad de las reuniones del Eurogrupo y del Semestre Europeo.

Las consecuencias del enfoque unilateral del fortalecimiento de la Gobernanza Económica Europea (GEE) como único aliciente para la recuperación de los sistemas de bienestar nacionales se han materializado, con el paso del tiempo, en una doble descomposición de las estructuras de legitimación de

${ }^{2}$ El 16 de enero, el Parlamento británico votó por 432 votos en contra del acuerdo para la salida del Reino Unido alcanzado con la UE. Actualmente, la premier británica, está tratando de buscar una alternativa neutral, dada la fuerte oposición al acuerdo incluso entre las filas de su propio partido, que cuente con el respaldo mayoritario de Westminster. En esta tesitura, las alternativas barajadas por algunos diputados conservadores y laboristas pasan por solicitar a la Unión una ampliación del artículo 50 del Tratado de la Unión Europea, la salida abrupta sin acuerdo, o la celebración de un segundo referéndum. Esta última opción resultaría factible tras dictaminar el Tribunal de Luxemburgo, el 10 de diciembre de 2018, en el Asunto C-621/18, Wightman y otros (ECLI:EU:C:2018:999), que el artículo 50 debe interpretarse en el sentido de que, cuando un Estado miembro ha notificado al Consejo Europeo, de conformidad con dicho artículo, su intención de retirarse de la Unión, el artículo autoriza al Estado miembro (mientras no haya entrado en vigor el acuerdo de retirada celebrado entre dicho Estado miembro y la UE o, en su defecto, mientras no haya expirado el plazo de dos años previsto en el artículo 50, apartado 3, del TUE, eventualmente prorrogado con arreglo a dicho apartado) a revocar unilateralmente, de manera inequívoca e incondicional, la notificación mediante comunicación dirigida por escrito al Consejo Europeo, una vez que el Estado miembro de que se trate haya adoptado la decisión de revocación con arreglo a sus normas constitucionales. La finalidad de la revocación es confirmar la pertenencia a la UE del Estado miembro en condiciones que no modifiquen su estatuto de Estado miembro, y poner fin al procedimiento de retirada. 
las instituciones públicas internas y europeas. Por una parte, a escala nacional se concretan en: una desregulación de los mecanismos de protección y asistencia social de los Estados miembros (EEMM); un incremento de la fragmentación de las tipologías contractuales y del precariado, como nueva clase social surgida al albur de la crisis del capitalismo financiero ${ }^{3}$; una erosión de las dinámicas relacionales mayorías-minorías, generando desafección ciudadana tanto con el funcionamiento como con las acciones de los órganos constitucionales. Esta pérdida de confianza es fruto, en gran medida, de una configuración asimétrica del parlamentarismo racionalizado donde la estabilidad y la gobernabilidad gozan de primacía frente al control y participación ciudadana $^{4}$. A ello habría que añadir que, en las últimas décadas, asistimos a un proceso de privatización progresiva de los espacios de toma de decisiones autonómico y estatal, con la aquiescencia de los Estados, donde la ciudadanía se limita a ser espectadora pasiva. Por otra parte, a nivel europeo se refleja en el déficit endémico del constitucionalismo de mercado europeo, la integración de lo social a través de mecanismos de regulación indirecta que confinan a este a un espacio condicional y restringido a su funcionalidad a las coordenadas del mercado interior. La atonía de la dimensión social en los instrumentos de la GEE renovada representa el mejor banco de pruebas de una integración positiva limitada por su abstracción a los márgenes del Derecho de la Unión (DUE) $)^{5}$. Además, puede consumarse el logro de un significativo número de escaños en la próxima eurocámara por movimientos políticos que cuestionan los valores adscritos a las tradiciones constitucionales comunes a los EEMM y amenazan con subvertir el orden supranacional europeo demandando una des-europeización del proceso en clave nacional popular ${ }^{6}$.

${ }^{3}$ Guy, Standing, The precariat. The new dangerous class (London: Bloomsbury Academic, 2011), 31-49.

${ }^{4}$ Daniel Innerarity Grau, « La representación de los europeos: sobre la posibilidades y límites de la parlamentarización de la Unión Europea», Cuadernos Europeos de Deusto, n. ${ }^{\circ} 56$ (2017): 166, doi: http://dx.doi.org/10.18543/ced-56-2017.

5 Ainhoa Lasa López, « Constitución económica europea y modelo social: límites e ineficiencias de la integración negativa mejorada en la lucha contra la exclusión social», Cuadernos Europeos de Deusto, n. 53 (2015): 159-161. En sentido contrario, destacar aquellas reflexiones para las que la presencia de lo social fuera de la arquitectura competencial de la política social europea (principalmente, mediante el recurso a una lectura condicionada de los valores sociales por las libertades económicas y el potencial transversal de la igualdad formal) se ha traducido, con matices, en un impacto positivo en materia de objetivos sociales. Elise Muir, «Drawing positive lessons from the presence of "The Social" Outside of EU Social Policy stricto sensu», European Constitutional Law Review, n. ${ }^{\circ} 1$ (2018): 78-84, https:// doi.org/10.1017/S1574019618000020.

6 Dídac Gutiérrez-Peris, «New Realignment of Fears in France and Europe», Cuadernos Europeos de Deusto, n. ${ }^{\circ} 59$ (2018): 103-104, doi: http://dx.doi.org/10.18543/ced-592018pp99-114. 
En esta tesitura, la, aun ambigua, aceptación en los programas de trabajo de la Comisión de $2016^{7}, 2017^{8}$, y $2018^{9}$, del carácter anacrónico del mantra del mercado interior como fuente generadora de bienestar para la ciudadanía europea, refleja un relato más proclive a suavizar el discurso de la neutralidad de la desigualdad estructural inherente a la jerarquía incondicionada del vínculo económico europeo. Las indicaciones de tiempo, dinámica y caracteres de los contenidos propositivos de los programas y documentos de reflexión parecen querer alejarse de la retórica mecanicista de las tutelas del mercado, aceptando las carencias de la dimensión social europea y su necesaria corrección. Un, aparentemente, renovado enfoque de reconfiguración de la integración social presente en el Pilar Europeo de Derechos Sociales ${ }^{10}$ proclamado, solemnemente, en la Cumbre Social de Gotemburgo en favor del empleo justo y el crecimiento ${ }^{11}$. Siguiendo estas premisas, la aproximación al modelo social europeo que realizan los textos políticos mencionados nos sitúa en un plano de supuesta revisión de sus coordenadas tradicionales. No obstante, para valorar la mayor o menor magnitud de la integración social revisada es preciso hacer referencia, previamente, a la exégesis y evolución del modelo para, posteriormente, confrontarla con el marco propositivo de los documentos de trabajo y de reflexión post-crisis.

En este sentido, desde los orígenes del proceso de integración la dimensión social estuvo presente en una construcción ya basada en su funcionalidad a las variables del mercado común en formación. En particular, aquellos aspectos del mercado de trabajo que conectaban directamente con el establecimiento de un mercado común, principalmente la proximi-

${ }^{7}$ Comunicación de la Comisión al Parlamento Europeo, al Consejo, al Comité Económico y Social Europeo y al Comité de las Regiones. Programa de trabajo de 2016. No es momento de dejar las cosas como están. Estrasburgo, 27 de octubre de 2015. COM (2015) 610 final.

${ }^{8}$ Comunicación de la Comisión al Parlamento Europeo, al Consejo, al Comité Económico y Social Europeo y al Comité de las Regiones. Programa de Trabajo de la Comisión para 2017. Realizar una Europa que proteja, capacite y vele por la seguridad. Estrasburgo, 25 de octubre de 2016. COM (2016) 710 final.

${ }^{9}$ Comunicación de la Comisión al Parlamento Europeo, al Consejo, al Comité Económico y Social Europeo y al Comité de las Regiones. Programa de trabajo de la Comisión para 2018. Estrasburgo, 24 de octubre de 2017. COM (2017) 650 final.

10 «Informe Final. Cumbre social en favor del empleo justo y el crecimiento. Gotemburgo, Suecia, 17 de noviembre de 2017», acceso el 9 de diciembre de 2018, https://www.government.se/4933fd/contentassets/70800fb59e6c43829c115ca73fb94b6e/concluding-reportgothenburg-summit.pdf.

11 «Pilar Europeo de Derechos Sociales», acceso el 9 de diciembre de 2018, https:// ec.europa.eu/commission/sites/beta-political/files/social-summit-european-pillar-socialrights-booklet_es.pdf. 
dad del trabajo como factor de producción al devenir del sistema empresarial y productivo, fue lo que llevó a la temprana aprobación de normas relativas al empleo y al mercado del trabajo en el ámbito comunitario. Se trataba, por lo tanto, de una configuración de lo social bajo la batuta de un mercado mercantilmente unificado. Desde entonces, el iter evolutivo de la integración social conectaría con los cambios actuados en la integración económica (constitución económica) del constitucionalismo de mercado, constitución material del proceso de integración. Esta primera fase de paulatina intervención en el ámbito de la política social, donde lo social tiene una cierta presencia vinculado a una de las libertades básicas (libre circulación de trabajadores) que presiden normativamente la construcción del mercado común, se concretó en el dispositivo referente a la seguridad social de los trabajadores emigrantes y a la formación y titulaciones profesionales, así como en la adopción de medidas de impulso y sostén de programas de cualificación y movilidad de la mano de obra. La movilidad laboral constituía así la piedra angular de la integración positiva de los Tratados Constitutivos de las Comunidades Europeas ${ }^{12}$. Habrá de esperarse al Tratado de Ámsterdam para que lo social comience a tener una presencia más notable en el ordenamiento jurídico comunitario, si bien, a través de un sistema de reenvío normativo a la Carta Social Europea de 1961, y a la Carta Comunitaria de derechos sociales fundamentales de los trabajadores de 1989, de escasa eficacia jurídica. Paralelamente, en el plano de la política de empleo se continúa incidiendo en ámbitos de intervención indirecta ${ }^{13}$. El último episodio se produce con la Carta de Derechos Fundamentales de la Unión (CDFUE) y el reconocimiento de su naturaleza de derecho originario por el artículo 6.1 del actual Tratado de la Unión Europea (TUE). En el Título IV, Solidaridad, se contemplan el grueso de derechos prototípicos del Estado social, aunque con una formulación propia de los cánones programáticos que reproduce el sistema de reenvíos al ámbito infraconstitucional, verdadero espacio de materialización de las políticas (sociales y de empleo) que no de los derechos. Empero, estas últimas incorporaciones al DUE han sido consideradas por cierto sector doctrinal como un cambio de paradigma en la Europa social basada, hasta el Tratado de Maastricht, y, sobre todo de Ámsterdam, en la garantía y protección unilateral de los derechos de los y las trabajadores y

12 Jeff Kenner, «Employment and macroeconomics in the EC Treaty: a legal and political symbiosis?», Maastricht journal of European and comparative law, n. ${ }^{\circ} 4$ (2000): 376-379, https://doi.org/10.1177/1023263X0000700404.

13 Janine Goetschy, «The European Employment Strategy: genesis and development», European Journal of Industrial Relations, n. ${ }^{\circ} 2$ (1999): 122-123, https://doi. org/10.1177/095968019952002. 
trabajadoras, hacia una Europa social abierta a nuevas dimensiones más allá de los tradicionales planteamientos economicistas ${ }^{14}$.

Descendiendo al ámbito legislativo supranacional, es oportuno precisar que en el conjunto de la normativa social europea no todos los actos legislativos tienen el mismo significado y alcance, pudiendo distinguirse entre aquella regulación que constituye un derecho único o propio de la Unión, y la que se incorpora a los derechos nacionales o los sustituye, como es el caso de las normas relativas a la libre circulación de trabajadores. A su vez, encontramos dispositivo social de la Unión que concierne a realidades ya reguladas por los derechos internos y cuya finalidad es el establecimiento de una regulación de mínimos para orientar la acción legislativa de los Estados. Este sería el caso de las directivas comunitarias conexas a la participación de los trabajadores o el diálogo social. Junto a estas, se han de señalar las normas de coordinación distinguiendo la doble dimensión que el término adopta en la terminología social de la Unión. Por un lado, aquella coordinación de tipo normativo e institucional dirigida a la determinación del sistema nacional aplicable a un determinado supuesto y a la solución de los problemas administrativos e institucionales como consecuencia de la implicación de varios sistemas, como son el conjunto de disposiciones relativas a la seguridad social de los trabajadores emigrantes. Por otra parte, nos encontramos con el Método Abierto de Coordinación (MAC) que afecta sobre todo a la política de empleo y de protección social de la Unión. Su fuente de expresión preferente son las orientaciones o recomendaciones, técnicas de soft law ${ }^{15}$.

Paralelamente a estas precisiones sobre la naturaleza jurídica de las distintas normas que componen el modelo social europeo, surge la necesidad de interrogarse sobre el tipo de relación existente entre la integración social y la integración económica en el orden europeo. Como acabamos de señalar, la integración positiva en el espacio supranacional se constituye desde sus orígenes como dinámica funcional (factor), es decir, como objeto y no como sujeto. Esto implica que en el plano europeo el lenguaje jurídico-político se desenvuelva en términos de compatibilidad entre ambas instancias y no de conflicto. Fundamentalmente, porque tras esa compatibilidad está presente el estigma de un modelo social que, pensado y configurado en coherencia con los condicionantes de la integración económica, no ofrece

${ }^{14}$ En este sentido, Claire Kilpatrick, « The displacement of Social Europe: a productive lens of inquiry», European Constitutional Law Review, n. ${ }^{\circ} 1$ (2018): 62-74, https://doi. org/10.1017/S1574019618000019.

15 David M. Trubek y Louise. G Trubek, «Hard and soft law in the construction of social europe: the role of the open method of co-ordination», European Law Journal, n. ${ }^{\circ} 3$ (2005): 351-356, https://doi.org/10.1111/j.1468-0386.2005.00263.x. 
ningún tipo de resistencia. Modulado en torno al paradigma del mercado común y a su compatibilidad subalterna con el mismo, el modelo social de la Unión presenta unos perfiles que chocan con los de su homólogo en el ámbito de los derechos nacionales vinculado a los parámetros del Estado social. Estas son las conclusiones a las que, a nuestro parecer, conduce la lectura de la dimensión social realizada por las instituciones de la UE.

Concretamente, adoptar como posible modelo de representación de la relación entre la integración social y la integración económica el de la «coexistencia o complementariedad», implica atenuar las divergencias de las que pudieran ser portadores cada uno de los sistemas normativos. El nexo de unión entre ambos sistemas viene representado por la racionalidad económica funcional a los objetivos extra-sociales consistentes en la disciplina del mercado del trabajo y la regulación de la competencia entre empresas y trabajadores, como contenido propio de la integración positiva. Desde esta óptica, esta última, además de su matriz social sería, al mismo tiempo, una forma de regulación de la competencia transnacional vía reducción de la competencia entre trabajadores a través de la eliminación de las diferencias de desarrollo y de coste de los respectivos sistemas de protección social nacionales y de tutela del trabajo capaces de desvirtuar o distorsionar el juego competencial entre los EEMM. De tal forma que los objetivos y las políticas sociales y de empleo que conforman el modelo social europeo no solo actuarían como mecanismos de protección de los sistemas de trabajo y de seguridad social nacionales, sino que tendrían como función esencial eliminar la práctica de formas incontroladas de dumping social. Se trata de garantizar la compensación de las condiciones de competencia de las empresas que actúan en el mismo sector económico equiparando los costes de adquisición de la fuerza del trabajo. Aspecto que modula lo social como complemento de la integración económica y sus correlatos de la libre competencia. En esta función de garantía del restablecimiento de las condiciones de competencia leal a través de la técnica de la aproximación de las legislaciones laborales internas es indudable que la integración económica y social convergen en una singular relación caracterizada por la subsidiariedad de la segunda con respecto a la primera, en cuanto funcional al correcto funcionamiento del mercado. Esta relación de coexistencia o complementariedad tiene en la aproximación funcional la fuente de legitimación de las políticas sociales y de empleo del derecho primario. De tal forma que la complementariedad entre los sistemas se explica por la lógica casi exclusivamente económica del dispositivo social de la Unión en conexión con los principios de la libre competencia.

Revertir esta regulación social indirecta convergente con la filosofía de la economía social de mercado altamente competitiva, elemento vertebrador y condicionante de las políticas sociales y de empleo, para conformar un modelo social autónomo con capacidad de actuar una regulación directa 
es la tesis que, consideramos, permitiría interiorizar «otra» Europa social desmarcándose de la senda de desconstitucionalización social en clave interna de la integración económica, y articular verdaderos espacios de garantía y tutela de la ciudadanía social de la Unión en el orden supranacional europeo. No es una simple cuestión de ampliar el ámbito de acción de la integración positiva a otras materias desvinculadas de los mercados de trabajo internos, tampoco de explorar los potenciales beneficios de las lecturas accesorias de los derechos sociales a las libertades económicas fundamentales, trazando un cierto paralelismo con el enfoque objetivo de los derechos civiles y políticos del Tribunal Europeo de Derechos Humanos. Se trata de supranacionalizar un constitucionalismo de signo opuesto al del mercado. Para ello, resulta de especial interés acercarse a los contenidos de las propuestas y documentos de reflexión adoptados por la Comisión en el trienio de 2016 a 2018, reflexionar sobre su calado y determinar si estamos asistiendo a una reversibilidad de la jerarquía incondicionada de las conquistas del vínculo económico europeo. Siguiendo este esquema, en el segundo apartado abordaremos las directrices en materia social correspondientes al programa de trabajo de la Comisión de 2016, condensadas en torno a la formulación de la movilidad laboral. En el tercer apartado nos centraremos en el documento de reflexión de abril de 2017 sobre el futuro de la integración social de Europa, donde se alternan las opciones de una dimensión social de geometría variable con alternativas más específicas consistentes en reconducir la integración social al limitado marco de las libertades económicas. En el cuarto apartado, analizaremos uno de los documentos llamado a impulsar los derechos sociales en el espacio supranacional europeo, con especial incidencia en la zona del euro. El Pilar Europeo de Derechos Sociales y los principios y derechos que lo integran tratan de revitalizar el acquis social comunitario desde una óptica que combina los elementos más característicos del factor trabajo, movilidad y condiciones justas y equitativas, con otros exógenos a los vectores tradicionales de los mercados laborales, como el acceso a la vivienda o la ayuda social. En el quinto apartado se exploran las potencialidades del programa de trabajo de la Comisión para 2018. En particular, las acciones que concretan el paquete de equidad social, como son: la propuesta de revisión de la Directiva sobre la información por escrito por la que se establece la obligación del empresario de informar a los trabajadores acerca de las condiciones aplicables al contrato de trabajo o la relación laboral; la propuesta de recomendación relativa al acceso a la protección social para los trabajadores por cuenta ajena y los trabajadores por cuenta propia; y la propuesta de creación de una Autoridad Laboral Europea. La contribución terminará con unas consideraciones finales a propósito de la idoneidad de los textos y medidas legislativas apuntadas para garantizar una dimensión social «incondicional» en y de Europa. 


\section{Paquete de movilidad laboral 2016: Un mercado interior más justo y más profundo con una base industrial fortalecida}

El programa de trabajo de la Comisión de 2016, titulado «No es el momento de dejar las cosas como están», responde a la adopción de iniciativas legislativas y no legislativas que impulsen las diez prioridades para 20152019 establecidas en la Agenda en materia de empleo, crecimiento, equidad y cambio democrático ${ }^{16}$, declaración de objetivos de la Comisión Juncker de 15 de julio de 2014. En lo que interesa, y con relación al cuarto ámbito político de las orientaciones, «Un mercado interior más justo y profundo, con una base industrial fortalecida», se hace hincapié en la libre circulación de trabajadores como pilar fundamental para fomentar la movilidad laboral; junto con el compromiso de revisar la Directiva sobre desplazamiento de trabajadores para evitar el dumping social, de forma que, «en nuestra Unión, el mismo trabajo en el mismo lugar debería tener idéntica retribución». Para materializar estas y otras directrices vinculadas a la libre circulación de trabajadores y trabajadoras, la Comisión Europea anunciaba en el Anexo $\mathrm{I}^{17}$ del programa de 2016 nuevas iniciativas, y, entre ellas, la octava relativa al mercado interior constaba de una comunicación sobre la movilidad laboral, una revisión de la Directiva sobre el desplazamiento de trabajadores y una revisión de los Reglamentos sobre la coordinación de la seguridad social ${ }^{18}$.

Dada la naturaleza política de la comunicación, nos centraremos en la segunda y tercera de las iniciativas que se refieren a materias no exentas de polémica en cuanto a los intereses en juego. La segunda establece un difícil binomio entre libertad de circulación de trabajadores y trabajadoras y libre prestación de servicios que suaviza las garantías del factor de producción trabajo. La tercera, por su parte, incide en la tutela de las prestaciones sociales de los trabajadores y trabajadoras móviles y sus vicisitudes ante la diversidad y fragmentación de los sistemas de protección nacionales. Ambos aspectos requieren una respuesta común a escala europea que atenúe las reticencias de las visiones sociales contrapuestas entre EEMM: los partidarios de preservar a escala europea unas condiciones laborales parejas a los sistemas de bienestar nacionales más garantistas, y los detractores de aplicar

16 Estrasburgo, 15 de julio de 2014, http://europa.eu/rapid/press-release_SPEECH-14546_es.htm, acceso el 10 de diciembre de 2018.

17 Anexo de la Comunicación de la Comisión al Parlamento Europeo, el Consejo, el Comité Económico y Social Europeo y el Comité de las Regiones. Programa de trabajo de la Comisión de 2016. No es momento de dejar las cosas como están. Estrasburgo, 27 de octubre de 2015. COM (2015) 610 final.

${ }^{18}$ COM (2015) 610 final..., 3. 
legislaciones laborales que puedan generar limitaciones de la ventaja competitiva basada en bajos costes salariales. En el ámbito de la coordinación de los sistemas de seguridad social las mayores dificultades se centran en un tema tan complejo como propicio para alentar la discriminación intracomunitaria, como es el del acceso de la ciudadanía europea económicamente inactiva a las prestaciones sociales en los Estados receptores. Curiosamente, en este ámbito los países que se incorporaron a la Unión en las ampliaciones de las dos oleadas de 2004 y 2007 y los países de Europa Occidental intercambian los roles que mantienen en materia de trabajadores desplazados. Los primeros reclaman la centralidad incondicionada de la igualdad de tratamiento para la ciudadanía de la Unión; mientras que los segundos, apelan a las cargas económicas generadas por el turismo asistencial y la consiguiente puesta en peligro para el funcionamiento de sus sistemas de bienestar. La ciudadanía, cuyo estatus trasciende las libertades económicas para adoptar perfiles de participación política, social y cultural en la Unión, se convierte en el motivo central de las posiciones divergentes cuando lo cierto es que la legislación en materia de desplazamiento y coordinación se constriñe al mercado interior y sus libertades, cerrando el paso a la dimensión humana y sus condiciones materiales. Este es el punto de partida que ha de tenerse en cuenta para comprender los motivos del desplazamiento del principio de igualdad de trato en el marco de las libertades económicas. Lo relevante, como veremos, no es la tutela del estatus de ciudadanía, sino la modulación de dos visiones contrapuestas de la integración social que tratan de consolidarse a través de frágiles equilibrios en torno a una regulación indirecta de mínimos.

\section{Propuesta de Directiva del Parlamento Europeo y del Consejo que} modifica la Directiva 96/71/CE del Parlamento Europeo y del Consejo, de 16 de diciembre de 1996, sobre el desplazamiento de trabajadores efectuado en el marco de una prestación de servicios

La principal motivación de la revisión de la Directiva 96/71/CE ${ }^{19}$, tal y como se desprende de la exposición de motivos de la propuesta ${ }^{20}$, es hacer frente a prácticas desleales o colusorias y promover el principio salario igual a trabajo igual considerando el papel esencial desempeñado por el desplazamiento de trabajadores en la prestación de servicios transfron-

19 Directiva 96/71/CE del Parlamento y del Consejo, de 16 de diciembre de 1996, sobre el desplazamiento de trabajadores efectuado en el marco de una prestación de servicios (DO núm. L 18 de 21 de enero de 1997).

${ }^{20}$ Estrasburgo, 8 de marzo de 2016. COM (2016) 128 final, 1. 
terizos. La Directiva regula tres tipos de desplazamiento: la prestación directa de servicios por una empresa en el marco de un contrato de servicios, el desplazamiento intragrupo, y el desplazamiento mediante la cesión de un trabajador por una empresa de trabajo temporal establecida en otro Estado miembro. A tenor de las materias objeto de regulación señaladas, la disciplina de los fenómenos de desplazamiento temporal de trabajadores de un Estado miembro por parte de empresas establecidas en otro Estado miembro, y la garantía de la libre competencia entre las empresas de los diversos EEMM, revela una priorización de las libertades económicas y la competencia en detrimento de los derechos sociales de los trabajadores desplazados.

Bajo estas coordenadas, la Directiva fue anunciada por la Comisión en el Programa de acción relativo a la actuación de la Carta de Derechos Sociales Fundamentales de 1989, como instrumento para tutelar a los trabajadores desplazados y, sobre todo, para evitar la erosión de los estándares laborales de los países de acogida. Sin embargo, la Directiva no encontró su fundamento jurídico en las previsiones sociales del Tratado de la Unión Europea ni en el Protocolo sobre Política Social anexo al mismo, sino en los artículos 57 a 66, actuales 56 a 62 del Tratado de Funcionamiento de la Unión Europea (TFUE), que atribuyen a la UE competencia normativa al objeto de eliminar las restricciones que obstaculizan la libre prestación de servicios. Como consecuencia del fundamento jurídico elegido, no hay duda de que la directiva constituía un instrumento de política de la competencia y sólo indirectamente presentaba una naturaleza social. En este contexto, la Directiva seguía la estela de las tendencias regulativas indirectas de la integración social comentadas, constituyendo la expresión de un derecho flexible que se encuadraría en una línea de técnica de aproximación donde las excepciones o particularidades aparecen como instrumentos de flexibilidad controlada. Por una parte, la protección que para los trabajadores desplazados contemplaba el conjunto de normas vinculantes de condiciones de trabajo y empleo, también denominado núcleo duro de la Directiva $^{21}$, tenía un carácter de mínimos. Su finalidad no era tanto el establecimiento de un principio de paridad, que no prohibición de discrimi-

${ }^{21}$ Artículo 3.1 de la Directiva 96/71/CE: a) los períodos máximos de trabajo así como los períodos mínimos de descanso; b) la duración mínima de las vacaciones anuales retribuidas; c) las cuantías de salario mínimo, incluidas las incrementadas por las horas extraordinarias; la presente letra no se aplicará a los regímenes complementarios de jubilación profesional; d) las condiciones de suministro de mano de obra, en particular por parte de agencias de trabajo interino; e) la salud, la seguridad y la higiene en el trabajo; f) las medidas de protección aplicables a las condiciones de trabajo y de empleo de las mujeres embarazadas o que hayan dado a luz recientemente, así como de los niños y de los jóvenes; g) la igualdad de trato entre hombres y mujeres y otras disposiciones en materia de no discriminación. 
nación, entre los trabajadores locales y los trabajadores desplazados, sino asegurar una paridad de tratamiento entre las empresas que desarrollan una prestación de servicios transnacional y aquellas empresas del país de acogida. Una conclusión que se deduce de los pronunciamientos del Tribunal de Luxemburgo de 2007 y 2008 que dieron lugar al conocido como cuarteto Laval ${ }^{22}$. En ellos, las prescripciones mínimas de la Directiva han de superar el filtro de la restricción razonable o menor restricción, en la medida de lo posible, a la libre competencia empresarial, convirtiéndose así en el máximo límite permitido a la libre prestación de servicios. Por otra parte, por lo que respecta a la igualdad entre trabajadores locales y desplazados, esta aparece como formalmente instrumental a la primera y sólo eventualmente, puesto que la extensión a los segundos de la tutela de los primeros atañe únicamente a un número limitado de materias (las contempladas en el artículo 3.1 de la Directiva), mientras que para las otras es meramente opcional y, sobre todo, condicionada.

Pero lo sustancial del razonamiento del juez europeo es que estuvieran en juego elementos que conforman la dimensión colectiva más característica del derecho al trabajo (derecho de huelga, acciones colectivas, negociación colectiva, derecho a una retribución justa) tutelados como derechos fundamentales por las Constituciones de la segunda posguerra mundial, y que estos estuvieran llamados a medirse con las libertades económicas (libre prestación de servicios) no desde la perspectiva de dos derechos que gozando de un mismo estatus o situados sobre un mismo plano garantizan contenidos diversos entre sí que suponen que la realización de uno implica la lesión de otro; sino desde la perspectiva de un derecho nacional que, interpretado como potencialmente restrictivo de una libertad fundamental, opera desde la lógica de la excepción, siendo la regla general, a la que las libertades económicas están llamadas a garantizar, la de la libre competencia. Circunstancia detonante de las críticas que han suscitado tales pronunciamientos $^{23}$. No obstante, más trascendente que la subalternidad de los derechos sociales nacionales a las libertades económicas sería el propio grado de jerarquización que se reconoce entre estas, la libre circulación de tra-

${ }^{22}$ Sentencia del Tribunal de Justicia de 11 de diciembre de 2007, Asunto C-438/05. ECLI:EU:C:2007:772. Sentencia del Tribunal de Justicia de 18 de diciembre de 2007, Asunto C-341/05. ECLI:EU:C:2007:809. Sentencia del Tribunal de Justicia de 3 de abril de 2008, Asunto C-346/06. ECLI:EU:C:2008:189. Sentencia del Tribunal de Justicia de 19 de junio de 2008, Asunto C-319/06. ECLI:EU:C:2008:350.

${ }^{23}$ Silvana Sciarra, «Viking and Laval: Collective Labour Rights and Market Freedoms in the Enlarged EU», Cambridge Yearbook of European Legal Studies (2008): 563-580, https://doi.org/10.1017/S1528887000001440. Catherine Barnard, «Viking and Laval: An Introduction», Cambridge Yearbook of European Legal Studies (2008): 463-492, https://doi. org/10.1017/S1528887000001403. 
bajadores y la libre prestación de servicios, basado en el objetivo de una y otra libertad. Mientras que en la libre circulación de trabajadores la interdicción de discriminación aparece exclusivamente vinculada a la integración del mercado europeo, en la libre prestación de servicios el fin perseguido es sobre todo la liberalización de los sectores nacionales protegidos, incluidas las normas de derecho laboral nacional que puedan incidir en la efectiva realización de la libre prestación de servicios. La maximización de la competencia desplaza a la prohibición de discriminación y se constituye como el elemento clave de funcionamiento de esta libertad económica. De ahí que los estándares de tutela de la relación laboral más elevados sean vistos como una «carga económica adicional» que puede impedir, obstaculizar o hacer menos interesantes la ejecución de la prestación de servicios en el Estado miembro de acogida. El artículo 56 del TFUE al perseguir la realización de la libre competencia, que junto con la economía de mercado son los contenidos en los que se articula la decisión política fundamental del ordenamiento jurídico comunitario, se erige como libertad fundamental con un estatus jerárquico superior a aquel de la libre circulación de trabajadores. Interpretada la libre circulación de servicios como parámetro de desarrollo directo de uno de los valores constitucionales supranacionales, el Tribunal de Justicia (TJ) evita la prohibición de discriminación en base a la nacionalidad favoreciendo la configuración de lo social como espacio de competencia. La protección de la ventaja competitiva de los países con un menor coste social no es sino la protección del propio modelo social que se articula desde la instancia comunitaria, la solidaridad competitiva que se contrapone al modelo social de los EEMM heredero de la tradición del constitucionalismo social. Esta deriva maximalista hacia la libre prestación de servicios ha tratado de atenuarse por el TJ de la UE en ulteriores sentencias como el asunto Sähköalojen ammattiliittory ${ }^{24}$ que abre la vía a una incipiente «ciudadanía europea industrial» ${ }^{25}$ al reconocer que la Directiva 96/71/CE, a la luz del artículo 47 de la CDFUE, se opone a que una normativa del Estado miembro del domicilio de la empresa que ha desplazado trabajadores al territorio de otro Estado miembro, en cuya virtud se prohíbe la cesión de créditos que tengan su origen en las relaciones laborales, impida que un sindicato finlandés, Sähköalojen ammattiliitto, interponga un recurso ante un órgano jurisdiccional del segundo Estado miembro en el que se ejecuta el

24 Sentencia del Tribunal de Justicia de 12 de febrero de 2015, Asunto C-396/13. ECLI:EU:C:2015:86.

${ }^{25}$ Dagmar Schiek, «Perspectives on social citizenship in the EU: from status positivus to status socialis activus via two forms of transnational solidarity», en EU Citizenship and Federalism The Role of Rights, ed. por Dimitry Kochenov (Cambridge University Press, 2017), 366. 
trabajo para cobrar en nombre de los trabajadores desplazados créditos salariales en relación con el salario mínimo en el sentido de la Directiva y que le han sido cedidos de conformidad con el Derecho vigente en ese último Estado. Y, el asunto Regio-Post ${ }^{26}$ donde reconoce a las entidades regionales de los EEMM la facultad exigir a los licitadores de contratos públicos y a sus subcontratistas que abonen a sus trabajadores un salario mínimo establecido en dicho contrato público.

En el ínterin de los pronunciamientos entró en vigor la Directiva 2014/67/UE 27 llamada a complementar y reforzar la Directiva 96/71/CE, al prever instrumentos para combatir y sancionar el abuso, fraude y colusión en la prestación transfronteriza de servicios por trabajadores desplazados como son: criterios cualitativos caracterizadores de la existencia de un vínculo real entre el empleador y el Estado miembro de establecimiento (artículos 4.3 y 4.4); disposiciones de refuerzo y mejora de la cooperación administrativa entre las autoridades nacionales competentes en materia de desplazamientos (artículos 6,7 y 8 ); y medidas de control nacionales que pueden aplicar los EEMM cuando supervisan el cumplimiento de las condiciones de trabajo de los trabajadores desplazados (artículos 9 y 10).

Sin embargo, tanto de los razonamientos del juez europeo, como de los efectos de la transposición de la Directiva de 2014, se derivaba la necesidad de reformar la Directiva 96/71/CE tanto para clarificar su terminología, como para fortalecer sus sinergias con la Directiva sobre la garantía de cumplimiento. En este escenario se sitúa la propuesta de revisión de la Directiva cuyas modificaciones sustanciales se concretan en los siguientes términos:

- Desplazamientos de larga duración: se añade un nuevo artículo 2bis a la Directiva que aborda la legislación laboral aplicable a los trabajadores desplazados cuando la duración prevista o real del desplazamiento exceda de veinticuatro meses. Concluido ese tiempo se aplicará la normativa de trabajo del Estado miembro de acogida.

- Condiciones de trabajo: se suprime en el apartado 1 del artículo 3 la referencia a las «actividades contempladas en el anexo», lo que significa que los convenios colectivos de aplicación general

${ }^{26}$ Sentencia del Tribunal de Justicia de 17 de noviembre de 2015, Asunto C-115/14. ECLI:EU:C:2015:566.

27 Directiva 2014/67/UE del Parlamento Europeo y del Consejo, de 15 de mayo de 2014, relativa a la garantía de cumplimiento de la Directiva 96/71/CE, sobre el desplazamiento de trabajadores efectuado en el marco de una prestación de servicios, y por la que se modifica el Reglamento (UE) $n^{\circ}$ 1024/2012 relativo a la cooperación administrativa a través del Sistema de Información del Mercado Interior («Reglamento IMI»). Diario Oficial de la Unión Europea L 159 de 28 de mayo de 2014, L 159/11-L 159/31. 
representativos, regionales o sectoriales, deberán aplicarse a todos los trabajadores desplazados en todos los sectores de la economía con independencia de que las actividades figuren o no el anexo de la Directiva. Previamente, esta era la situación solo para los convenios colectivos de aplicación general en el sector de la construcción.

- Remuneración: se modifica el apartado 1 del artículo 3 sustituyendo la referencia a las «cuantías de salario mínimo» por una referencia a la «remuneración» que supone el deber de los EEMM de acogida de garantizar a los trabajadores desplazados en su territorio las condiciones de trabajo y empleo en materia de remuneración, incluido el incremento por horas extraordinarias. Además se añade un nuevo párrafo in fine que obliga a los EEMM a publicar en el sitio web oficial único a escala nacional los elementos de la remuneración aplicable a los trabajadores desplazados. Asimismo, siguiendo el criterio jurisprudencial del asunto Regio-Post los EEMM, sobre una base proporcional y no discriminatoria, podrán establecer que las empresas establecidas en el territorio de otro Estado miembro obligadas a subcontratar (por disposiciones legales, reglamentarias, administrativas o por convenios colectivos) solo con empresas que garanticen determinadas condiciones de trabajo y empleo por lo que respecta a la remuneración, también estén sujetas a la misma obligación con respecto a los subcontratos con empresas que desplazan trabajadores a su territorio.

- Trabajadores cedidos por empresas de trabajo temporal: en la propuesta de nueva redacción del apartado 9 del artículo 3 se especifica que las condiciones aplicables a las empresas transfronterizas que ceden trabajadores deben ser las mismas que se aplican a las empresas de trabajo temporal nacionales. Obligación legal impuesta a los EEMM frente a la tibieza de la redacción facultativa del citado apartado en la Directiva inicial, «Los Estados miembros podrán disponer».

\subsection{Directiva (UE) 2018/957 del Parlamento Europeo y del Consejo} de 28 de junio de 2018 que modifica la Directiva 96/71/CE sobre el desplazamiento de trabajadores efectuado en el marco de una prestación de servicios ${ }^{28}$

Publicada la propuesta de Directiva revisada de la Comisión se inició el procedimiento de tarjeta amarilla donde los parlamentos de 11 EEMM expusieron, a través de sus respectivos dictámenes motivados, sus posi-

28 Diario Oficial de la Unión Europea de 28 de junio de 2018, L 173/16-173/24. 
ciones sobre la misma. Lo relevante de esta fase del proceso de subsidiariedad fue la materialización de dos visiones opuestas en materia de movilidad laboral pero, sobre todo, que ponen de relieve una concepción de los derechos laborales que se mueve entre la flexiguridad y la explotación flexible. En ambos casos, la flexibilidad controlada de las garantías-tutelas laborales es el nexo de unión. Las diferencias radican, sin embargo, en el grado de seguridad vinculado a la flexibilidad, presente en el primero, ausente en el segundo. Desde esta perspectiva, los parlamentos de Alemania, Austria, Bélgica, Francia, Luxemburgo, los Países Bajos y Suecia dieron su respaldo a: la modernización de la Directiva sobre el desplazamiento de trabajadores para garantizar el principio de idéntica remuneración para el mismo trabajo en el mismo lugar; ampliar las disposiciones relativas a las condiciones socio-laborales aplicables a los trabajadores desplazados, especialmente en materia de remuneración; y, establecer una duración máxima para los desplazamientos para armonizar las disposiciones con el Reglamento de la UE sobre la coordinación de los sistemas de seguridad social. Paralelamente, los parlamentos de Bulgaria, Chequia, Eslovaquia, Estonia, Hungría, Letonia, Lituania, Polonia y Rumanía, se mostraron contrarios a la inclusión del principio de igual salario a trabajo igual argumentando que las diferencias salariales son un elemento legítimo de ventaja competitiva para los prestadores de servicios, y su supresión sería incompatible con el mercado único. A mayor abundamiento, con relación a la prestación transfronteriza de servicios por empresas de trabajo temporal, cuestionaban la legitimidad de la nueva redacción de la disposición novena del artículo 3 al perder los EEMM de origen su derecho a decidir sobre las condiciones laborales y de empleo, tal y como se contempla en la Directiva 2008/104/CE del Parlamento Europeo y del Consejo de 19 de noviembre de 2008 relativa al trabajo a través de empresas de trabajo temporal ${ }^{29}$.

Finalmente, el 21 de junio de 2018, el Consejo adoptó la Directiva revisada cuya fecha límite de transposición y aplicación será el 30 de julio de 2020. En la versión final se mantienen la mayoría de los elementos clave que propuso la Comisión en materia de remuneraciones y condiciones laborales aplicables a los trabajadores cedidos por empresas de trabajo temporal con una serie de modificaciones, añadiéndose nuevas disposiciones en materia de vigilancia y control. En primer lugar, la Directiva (UE) 2018/957, modifica el artículo 1 introduciendo dos tipos de disposiciones: la primera (1) contempla expresamente la obligación de garantizar a los trabajadores desplazados para la prestación de un servicio las condicio-

${ }^{29}$ Diario Oficial de la Unión Europea, de 5 de diciembre de 2008, L 327/9-L 327/14. 
nes de trabajo y la protección de la salud y la seguridad. Apostando por una definición más inclusiva de las distintas variables presentes en una relación laboral transfronteriza. La segunda de las disposiciones (1bis) se hace eco de las críticas de la academia al cuarteto Laval y establece, directamente, que la Directiva no afectará al ejercicio de los derechos fundamentales laborales de los países miembros y reconocidos por la Unión, «incluyendo el derecho o la libertad de huelga o de emprender otras acciones contempladas en los sistemas de relaciones laborales específicos de los Estados miembros, de conformidad con la legislación o las prácticas nacionales. Tampoco afecta al derecho a negociar, concluir y hacer cumplir convenios colectivos o llevar a cabo acciones colectivas conforme a la legislación o las prácticas nacionales».

En segundo lugar, en el apartado 1 del artículo 3 se incluye la igualdad de trato como base de la legislación laboral aplicable a los trabajadores transfronterizos, principio ausente en la propuesta de la Comisión. Así mismo, en el citado artículo se añade una nueva letra i) que reconoce, entre las materias del núcleo duro, «los complementos o los reembolsos en concepto de gastos de viaje, alojamiento y manutención previstos para los trabajadores que están fuera de su domicilio por motivos profesionales», precisando que tales gastos no podrán deducirse del salario de los trabajadores. En tercer lugar, con relación a las remuneraciones contempla sanciones para los EEMM que incumplan la obligación de publicar información actualizada y exacta sobre las condiciones de trabajo de los trabajadores desplazados. En cuarto lugar, la duración del desplazamiento se reduce de veinticuatro a doce meses (con una prórroga de seis meses) en el nuevo apartado 1 bis.

Es pronto para aventurar el impacto de la nueva directiva sobre desplazamiento de trabajadores, pero, por lo pronto, consideramos que la sustitución del país de origen por el del Estado miembro de acogida implica un avance cualitativo sustancial. No en vano, determinar la normativa aplicable en base al principio del país de origen o del Estado miembro receptor a los trabajadores dependientes de operadores económicos establecidos en un Estado miembro que, sin crear una ulterior sede jurídica y operativa en otro país de la Unión, proporcionan servicios en el territorio de un Estado miembro con su propio personal que es desplazado a este último de forma transitoria, no es algo intrascendente. Hasta la adopción de la Directiva renovada ni siquiera el principio de mutuo reconocimiento sobre el que se sustenta el dispositivo de la Directiva 2006/123/CE de 12 de diciembre de 2006, relativa a los servicios en el mercado interior ${ }^{30}$,

${ }^{30}$ Diario Oficial de la Unión Europea, de 27 de diciembre de 2006, L 376/36-L 376/68. 
permitía concebir a la tutela del trabajo como idónea, por sí misma, para comprimir legítimamente la libre circulación de servicios. No obstante la exclusión, a priori, del contenido indisponible del artículo 3.1 de la Directiva 96/71, el mutuo reconocimiento permite a las legislaciones nacionales, por un lado, introducir restricciones a la libre circulación de servicios sobre la base de exigencias imperativas de interés general, orden público, seguridad pública, salud pública o tutela del medio ambiente; y, por otro lado, salvaguardar el derecho del trabajo del país en el que el servicio viene prestado, dejando inalterado el orden normativo prefigurado por la directiva 96/71. Sin embargo, la previsión de la aplicación «conforme al derecho comunitario» de las restricciones a la libre prestación de servicios, junto con su subordinación al cumplimiento de una serie de requisitos (que no sean discriminatorios, injustificados o desproporcionados en relación al objetivo perseguido, artículo 16.3), y el reconocimiento a los EEMM de espacios muy reducidos para extender a los trabajadores desplazados las normativas internas del derecho del trabajo dado el carácter de prescripciones de mínimos en que se sustanciaban las previsiones del citado apartado 3 del artículo 1 de la Directiva 96/71 sobre trabajadores desplazados, se traducía en la reserva de amplios márgenes para una competencia entre empresas nacionales y empresas desplazadas sobre las condiciones normativas y el coste de la fuerza de trabajo empleada.

Ciertamente, hay aspectos de la nueva directiva que son cuestionables. Fundamentalmente, la condicionabilidad del disfrute de las condiciones laborales del país de acogida a que la duración del desplazamiento temporal supere los doce meses resulta contradictorio con la referencia al principio de igualdad de trato que exigiría un tratamiento equivalente entre trabajadores de origen y desplazados independientemente del criterio temporal. Sin embargo, este principio es solo un elemento orientador que se modula, diluyéndose, en atención al verdadero fundamento jurídico de la Directiva que continua siendo el artículo 56 del TFUE, la libertad de prestación de servicios. Los límites a esta libertad fundamental no son los propios de la igualdad de trato de la libre circulación de trabajadores, ni siquiera una más ambiciosa y más que nunca necesaria igualdad real y efectiva de la ciudadanía de la Unión, sino los propios del principio estructural de la libre competencia, su posible alteración a través de prácticas que promueven el dumping social es el fundamento de la Directiva renovada. Con todo, debemos reconocer que con la Directiva (UE) 2018/957 el riesgo de una migración de empresas prestadoras de servicios a la búsqueda continua de aquellos derechos nacionales que ofrecen una regulación de las relaciones laborales menos onerosa, aunque seguirá siendo una realidad, tendrá opciones más limitadas para su realización. 


\section{Propuesta de Reglamento del Parlamento Europeo y del Consejo} por el que se modifican el Reglamento (CE) $n .^{\circ} 883 / 2004$, sobre la coordinación de los sistemas de seguridad social, y el Reglamento (CE) $n . .^{\circ} 987 / 2009$, por el que se adoptan las normas de aplicación del Reglamento (CE) $n .^{\circ} 883 / 2004^{31}$

La revisión de la coordinación de los sistemas de seguridad social comenzó a fraguarse ante la posibilidad del triunfo del Brexit en base, entre otros motivos, al riesgo que suponía para la sostenibilidad del sistema de protección social el ejercicio no limitado de la libre circulación de trabajadores. Las concesiones a esta demanda se concretaron en el Anexo I de la Decisión de los Jefes de Estado o de Gobierno, reunidos en el seno del Consejo Europeo, relativa a un nuevo Régimen para el Reino Unido en la Unión Europea, adoptada en el seno de la reunión del Consejo Europeo celebrada los días 18 y 19 de febrero de $2016^{32}$. En particular, en la Sección D, Prestaciones Sociales y Libre Circulación, del citado Anexo I, se reconocían expresamente las inquietudes del Reino Unido ante la magnitud excepcional de los flujos de entrada de trabajadores de otros EEMM que podían generar una presión excesiva para el adecuado funcionamiento de sus servicios públicos ${ }^{33}$. El resto de EEMM, a excepción de los países de Europa Central y Oriental, lejos de manifestar su rechazo frente a una narrativa sesgada y oportunista de las causas del «Badfare state», aprovecharon la coyuntura para hacer valer la necesidad de una revisión proporcional y justificada de los Reglamentos n. ${ }^{\circ} 883 / 2004$ y n. $^{\circ} 987 / 2009$. Especialmente, en lo referente al acceso a las ayudas sociales destinadas a cubrir los costes mínimos de subsistencia de los trabajadores de la Unión económicamente inactivos, aun cuando dichas prestaciones estén previstas también para facilitar el acceso al mercado de trabajo en los EEMM de acogida.

La apuesta por un estatuto de la ciudadanía social excluyente, en tanto condicionado a la disposición de recursos suficientes para no convertirse en una carga para el sistema de asistencia social del Estado miembro receptor, contrasta frontalmente con el principio de igualdad de trato en su vertiente objetiva, conexa a las necesidades materiales, perfilando una ciudadanía europea condicionada por sus propias capacidades económicas, por más que esta interpretación haya sido avalada por el TJUE ${ }^{34}$. Huelga decir que, el

31 Estrasburgo, 13 de diciembre de 2016. COM (2016) 815 final.

32 Diario Oficial de la Unión Europea de 23 de febrero de 2016, C-69.

33 Ibidem, C-69 I/7-I/9.

${ }^{34}$ Isabel Lirola Delgado, «Derecho de residencia de los ciudadanos de la Unión y prestaciones sociales en tiempos de crisis: ¿Hacia un planteamiento casuístico y ambiguo de la solidaridad entre los Estados miembros?», Revista de Derecho Comunitario Europeo, n. ${ }^{\circ} 49$ (2015): 733-766. 
temor al denominado «turismo social» de la ciudadanía procedente de determinados países miembros, es fácilmente rebatible si recuperamos la razón principal de la Estrategia Europea para el Empleo gestada a finales de los noventa, donde la respuesta del espacio europeo a la globalización de los mercados se materializó en procesos liberalizadores de promoción de la competitividad entre los mercados de trabajo nacionales. El impacto directo de las nuevas políticas de empleabilidad de la Unión se concretó en una estrategia de intervención dirigida, en lo sustancial, al abandono de las tradicionales políticas de intervención estatal en la economía. Para cumplir el objetivo de maximizar la competencia de los mercados laborales nacionales, la moderación de los costes salariales se convirtió en el mecanismo más eficaz actuando sobre los salarios de forma que aumentaran menos rápidamente que en el pasado. La dinámica de esta estrategia de atracción de inversión extranjera empleando la devaluación salarial como ventaja competitiva fue la utilizada por las empresas de los nuevos EEMM de Europa Central y Oriental para ganar posiciones en la competencia del mercado con respecto a las empresas de los antiguos países miembros con mayores cotas de bienestar y tecnológicamente más avanzados. Si bien sus efectos pudieron ser virtuosos a corto plazo, a largo plazo la diversidad de modelos de protección social que incorporan las experiencias estatales en la construcción europea, reforzada por la ausencia de mecanismos de intervención directa centralizada en política social, se convirtió en un factor determinante para el agravamiento de la asimetría en las condiciones sociales de la ciudadanía de la Unión. El bajo coste del trabajo ha forzado y fuerza a la ciudadanía de estos países a emigrar hacia otros Estados en busca de oportunidades reales de mejora de sus expectativas de vida a través del ejercicio de la libre circulación de trabajadores. El problema surgió cuando la presión competitiva entre las fuerzas de trabajo nacionales y las procedentes de estos EEMM fue aprovechada por los propios Estados de acogida para ahondar en la segmentación de sus mercados de trabajo nacionales. De modo que las bondades de las ventajas sociales asociadas a la competencia entre factores de producción, ha terminado derivando en un modelo competitivo caracterizado por un fuerte desequilibrio social promoviendo una igualdad de trato «a la baja ${ }^{35}$.

En este contexto, la Comisión Europa presentó en diciembre de 2016 la última propuesta de modificación de los reglamentos relativos a la coordinación de los sistemas de seguridad social. La base jurídica de un sistema de coordinación se sitúa en el artículo 48 del TFUE, donde la seguridad so-

35 Isabel Lirola Delgado, «La sentencia Dano: ¿El punto final de los «malabarismos del TJUE en materia de libre circulación de los ciudadanos de la Unión inactivos económicamente?», Revista General de Derecho Europeo, n. ${ }^{\circ} 36$ (2015): 17-21. 
cial y su territorialidad representan una cuestión clave en la libertad de desplazamiento de los trabajadores de la Unión. Por ello, el citado precepto contempla las medidas a considerar para el establecimiento de la libre circulación de los trabajadores asignando a los sistemas de seguridad social dos objetivos: la acumulación de todos los períodos que tienen en cuenta las diferentes legislaciones nacionales para la adquisición y mantenimiento del derecho a las prestaciones, así como para el cálculo de estas (artículo 48 a); y el pago de las prestaciones a las personas que residan en los territorios de los EEMM (artículo 48 b). De tal forma que el derecho originario de la Unión no ha considerado la seguridad social como objeto de una específica y autónoma intervención supranacional europea, sino como un aspecto de la garantía de la libre circulación de los trabajadores en los límites en los que esta se manifieste funcional a los objetivos de liberalización del mercado de trabajo. En esta línea, los condicionamientos que se pueden derivar de los sistemas de protección social bien para una actuación efectiva de la libre circulación, bien por la evidente incidencia que los tratamientos de seguridad social y asistenciales pueden tener sobre la propensión o la conveniencia a aceptar trabajo en otros EEMM, constituyen el fundamento que ha inspirado los Reglamentos . $^{\circ} 883 / 2004$ (el «Reglamento de base») y n. ${ }^{\circ}$ 987/2009 (el «Reglamento de aplicación»), e inspira la nueva redacción que se propone. Concretamente, sobre la directa funcionalidad a las exigencias productivas de una libre competencia eficaz y eficiente, al tiempo que se insiste en una distribución justa y equitativa de la carga financiera entre los EEMM, el proyecto de Reglamento modificador se basa en una serie de ámbitos básicos para un proceso de modernización en la coordinación de los sistemas de la seguridad social que responda a la realidad social y económica de los países miembros:

- prestaciones por desempleo: se actualizan las normas sobre totalización, exportabilidad y coordinación para los trabajadores fronterizos y otros trabajadores transfronterizos (artículos 61, 64 y 65). Las principales modificaciones se sustancian en: la facultad de los EEMM de prorrogar el periodo de tiempo durante el que se autoriza a los demandantes de empleo a exportar sus prestaciones por desempleo hasta la finalización del periodo durante el cual tienen derecho a su percepción, frente al actual límite de 6 meses; la posibilidad de los EEMM receptores de exigir que la persona trabaje en su territorio, al menos, un mes con carácter previo a totalizar los periodos anteriores en los que trabajó antes de la solicitud de la prestación por desempleo (modificación del artículo 61). En caso contrario, la totalización corresponderá al Estado miembro donde la persona haya trabajado anteriormente, al menos, durante un mes. Finalmente, el Estado 
miembro responsable de proporcionar las prestaciones por desempleo será aquel donde la persona desempleada hubiera tenido el último empleo durante, al menos, tres meses, frente a la actual redacción donde la responsabilidad recae en el Estado de residencia.

- prestaciones por cuidados de larga duración: se introduce un capítulo aparte (en la letra i), punto 1, inciso ii), a continuación de los términos «Capítulo 1 del Título III sobre prestaciones de enfermedad, de maternidad y de paternidad asimiladas» se insertan los términos «y capítulo 1 bis, sobre prestaciones por cuidados de larga duración» sobre la coordinación de estas prestaciones que se ajusta a las disposiciones vigentes sobre prestaciones por enfermedad, incluyéndose una definición de prestaciones por cuidados de larga duración (letra d), y una lista de prestaciones nacionales (Anexo II del Reglamento de base modificado). Hasta ahora, este tipo de prestaciones no se habían incluido explícitamente en el Reglamento de base.

- prestaciones familiares: se distingue entre prestaciones en metálico cuya finalidad es sustituir los ingresos no percibidos por dedicarse a la crianza de hijos y todas las demás prestaciones familiares (artículo 68 ter).

- acceso a las prestaciones sociales por parte de ciudadanía móvil que no ejerza una actividad económica: se modifica el artículo 1 del Reglamento (CE) n. ${ }^{\circ} 883 / 2004$, Reglamento de base, insertándose el considerando 5bis que codifica el estado del Derecho de la UE tal como lo interpreta el Tribunal de Luxemburgo, clarificando la aplicación de la Directiva 2004/38/CE del Parlamento Europeo y del Consejo, de 29 de abril de 2004, relativa al derecho de los ciudadanos de la Unión y de los miembros de sus familias a circular y residir libremente en el territorio de los Estados miembros por la que se modifica el Reglamento (CEE) n. ${ }^{\circ} 1612 / 68$ y se derogan las Directivas 64/221/CEE, 68/360/CEE, 72/194/CEE, 73/148/CEE, 75/34/CEE, 75/35/CEE, 90/364/CEE, 90/365/CEE y 93/96/CEE ${ }^{36}$.

Resumidas las principales modificaciones, el 21 de junio de $2018^{37}$, el Consejo acordó su posición sobre la revisión del Reglamento estando, actualmente, en la fase de negociación a la espera de que el PE apruebe su

36 Diario Oficial de la Unión Europea, de 30 de abril de 2004, L 158/77-L 158/123.

${ }^{37}$ Coordinación de los sistemas de seguridad social: el Consejo acuerda una orientación general (comunicado de prensa): https://www.consilium.europa.eu/es/press/pressreleases/2018/06/21/coordination-of-social-security-systems-council-agrees-general-appro$\mathrm{ach} /$, acceso el 11 de diciembre de 2018. 
posición. En todo caso, se incorporen o no nuevas modificaciones o las revisiones descritas sean objeto de algunos cambios, la propuesta continua apostando por un estatus de ciudadanía como forma de movilidad inmediatamente funcional a instancias productivas, por un modelo social de inclusión condicionada vigente desde los Tratados Constitutivos de las Comunidades Europeas.

\section{Documento de reflexión sobre la dimensión social de Europa ${ }^{38}$ : minimalismo, descentralización, renacionalización o socialización del proyecto de integración}

El presente documento se diferencia de los actos legislativos adoptados o en previsión de adopción en materia de integración social europea que hemos detallado hasta el momento, en que se mueve en un plano más general o de abstracción, si se prefiere, en tanto en cuanto su finalidad es apuntar los posibles escenarios u opciones para la futura dimensión social en la Europa de los 27 en 2025. Por lo tanto, nos movemos en el ámbito de la discusión reflexiva frente a los debates propios de los procesos decisorios y legislativos donde las posturas divergen entre una regulación de mínimos al alza o una regulación indirecta donde la mejora de las condiciones laborales y de empleo no tienen cabida al circunscribirse al funcionalismo más ortodoxo de las dinámicas del mercado único.

Siguiendo la lógica del Libro Blanco sobre el futuro de Europa ${ }^{39}$, la Comisión Europea plantea las siguientes tres posibilidades para el futuro de la dimensión social:

- Limitar la dimensión social a la libre circulación renacionalizando las, hasta el momento, insuficientes competencias de la UE en las políticas sociales y de empleo (páginas 24-25 del Documento): esta opción ha estado presente en algunas de las posiciones mantenidas en las consultas a las partes interesadas y las evaluaciones de impacto, entre otras, de la Directiva (UE) 2018/957 sobre trabajadores desplazados para la prestación de servicios. Alterna el proteccionismo de la soberanía social nacional, entendida como devolución a los Estados de las competencias exclusivas y excluyentes de los sistemas de asistencia, protección social y condiciones de trabajo; con visiones propias del determinismo neoliberal de devaluación de los mecanismos de garantía de las legislaciones laborales internas para amortizar

38 Comisión Europea COM (2017) 206 de 26 de abril de 2017.

39 Comisión Europea COM (2017) 2025 de 1 de marzo de 2017. 
las ventajas competitivas de los bajos costes salariales. La mezcla extraña y confusa entre renacionalización, con vistas a materializar el recalcitrante populismo nacionalista, y el liberalismo más radical. Sin lugar a dudas, el peor de los escenarios posibles para la integración positiva europea ${ }^{40}$.

- Los que desean hacer más en el ámbito social hacen más o dimensión social de geometría variable en función de las capacidades socio-económicas y las sensibilidades políticas para con la integración social supranacional europea en los EEMM (páginas 26 y 27 del Documento): esta opción se plantea básicamente para los miembros de la zona del euro considerando los bruscos ajustes en los niveles de vida de la ciudadanía de estos países en los años de crisis. El objetivo sería alcanzar una mayor convergencia de las políticas de empleo y sociales nacionales a través de la fijación de estándares comunes de naturaleza preventiva. Las materias objeto de adaptación común se centrarían, sobre todo, en los mercados de trabajo, la competitividad, el entorno empresarial y la administración pública. De adoptarse este segundo escenario, los efectos secundarios se concentrarían en una polarización de lo social en el eurosistema con un mayor riesgo de fragmentación de estándares sociales con relación a los países no pertenecientes a la zona del euro. Las probabilidades de incrementos en las prácticas de competencia desleal aumentarían, con las consabidas repercusiones en la convergencia social entre Estados. Al margen de esta lectura propiamente ordoliberal sobre las consecuencias negativas para el mercado único y la libre competencia ante una desregulación incontrolada de aquellos aspectos sociales con directa afectación al vínculo económico, la descentralización flexible de la integración social ahondaría las asimetrías de la ciudadanía social de la Unión.

- La UE-27 podría profundizar en la dimensión social conjuntamente o Europa (más política) más social (páginas 28 y 29 del Documento): esta sería la opción deseable en tanto en cuanto permitiría desarrollar estrategias sociales de alcance general para el conjunto de países de la Unión. El problema es que en las aportaciones del documento no se establece con claridad si la voluntad política conjunta se mantendrá en el mínimo común denominador, reduciendo la convergencia a nivel residual en

40 European Trade Union Confederation, «Reflection Paper on the Social Dimension of Europe». ETUC Assessment (position). Adopted at the ETUC Executive Committee on 13-14 June 2017 , p. 7 
aquellos EEMM con mayores niveles de garantías en la regulación de los mercados de trabajo, ni tampoco si los países miembros de más reciente incorporación se verán obligados a implementar normativa laboral más garantista, además de los estándares mínimos comunes. La ausencia de referencias a mecanismos vinculantes, solo se habla de valores, aspecto axial difícilmente objetivable en términos jurídico-normativos, la ambigua mención a una futurible necesidad de revisar el actual equilibrio de competencias entre la Unión y los EEMM, junto con el referente de la economía social de mercado como centro de gravedad de la actuación en el ámbito social, arroja serias dudas sobre la futura concreción del tercer escenario y la viabilidad de una convergencia al alta en consonancia con la propuesta del Presidente Juncker de una Triple A social para Europa.

Quizás la mención expresa, como parámetro vinculante de referencia, de una cláusula de no regresión, junto con una propuesta precisa de redefinición del principio de igualdad de trato sin fisuras en materia de acceso a prestaciones sociales en todos los países miembros, contribuiría a reforzar la identificación de la ciudadanía europea con el proyecto de la Unión y, sobre todo, a garantizar la viabilidad de una dimensión social que deje de situarse en una posición subalterna con respecto a la integración económica. No obstante, las ausencias en el texto de reflexión para ahondar en esta reconfiguración de la integración social como dimensión autónoma son especialmente significativas. La falta de un análisis macroeconómico sobre los orígenes y causas de la crisis del euro y sus restricciones a la dimensión social la debilita. A ello habría que añadir la falta de reconocimiento, como instrumentos cruciales para la realización de la integración positiva europea, de las medidas adscritas a la dimensión colectiva, fundamentalmente la negociación y la acción colectiva. La tradicional función normativa de garantía pública de la integración económica del trabajo de la negociación colectiva en el Estado Social actúa restringiendo la competencia entre los trabajadores a través de la imposición de estándares mínimos uniformes que inhiben a los empresarios de comprimir el coste de los recursos humanos por debajo de los mismos. Esta determinación del tratamiento de mínimos se traduce en un vínculo para el empresario al que no le quedan espacios de autonomía de negociación presentes en este ámbito para recuperar márgenes de competitividad con respecto a sus competidores. De forma tal que la negociación colectiva a escala supranacional, cumpliendo estas coordenadas, sería el mecanismo más eficaz para garantizar la homogeneidad al alta de los estándares de empleo, seguridad y salud en el trabajo. Por úl- 
timo, el análisis que se hace sobre el empleo en la fase post-crisis es engañoso al sobrestimar la recuperación de los mercados de trabajo nacionales cuando esta se ha producido a costa de un aumento del precariado. De cualquier manera, y más allá de estas consideraciones valorativas sobre las tres posibles opciones de la futura integración social propuestas por la Comisión Europea, habrá de esperarse al resultado que arrojen las elecciones europeas de mayo de 2019 para conocer el escenario finalmente elegido.

\section{El Pilar Europeo de Derechos Sociales: ¿isonomía de los objetivos sociales y las libertades económicas?}

El 9 de septiembre de $2015^{41}$, se anunció el desarrollo de un pilar europeo de derechos sociales dirigido a fomentar en la zona del euro mercados de trabajo y sistemas de protección social equitativos y que funcionen correctamente. El 25 de octubre de 2016, dentro del Programa de Trabajo de la Comisión para 2017, «Realizar una Europa que proteja, capacite y vele por la seguridad» ${ }^{42}$, y vinculada a la quinta prioridad, «Una Unión Económica y Monetaria más justa y sólida», se contemplaba la iniciativa número once de propuesta para un pilar de derechos sociales ${ }^{43}$. El 26 de abril de $2017^{44}$, la Comisión Europea presentaba su propuesta acerca del pilar acompañada del informe de la consulta pública a la ciudadanía, interlocutores sociales e instituciones de la Unión para evaluar sus puntos de vista sobre: a) la vigencia del acquis social comunitario y su acomodación a los desafíos presentes y futuros para un mercado laboral paneuropeo; b) los efectos condicionantes de la digitalización de los mercados de trabajo y el envejecimiento poblacional para el funcionamiento del mercado único; y, c)

41 Jean-Claude Juncker, «Estado de la Unión 2015: La hora de la sinceridad, la unidad y la solidaridad», acceso el 11 de diciembre de 2018, p. 10, http://europa.eu/rapid/press-release_SPEECH-15-5614_es.htm.

${ }^{42}$ COM (2016) 710 final, p. 11.

43 Anexo de la Comunicación de la Comisión al Parlamento Europeo, al Consejo, al Comité Económico y Social y al Comité de las Regiones. Programa de Trabajo de la Comisión para 2017. Realizar una Europa que proteja, capacite y vele por la seguridad. Estrasburgo, 25 de octubre de 2016. COM (2016) 710 final, p. 5.

${ }_{44}$ Comunicación de la Comisión al Parlamento Europeo, al Consejo, al Comité Económico y Social Europeo y al Comité de las Regiones. Establecimiento de un pilar europeo de derechos sociales. Bruselas, 26 de abril de 2017 COM (2017) 250 final. Documento de trabajo de los servicios de la Comisión que acompaña a la Comunicación de la Comisión al Parlamento Europeo, al Consejo, al Comité Económico y Social Europeo y al Comité de las Regiones. Establecimiento de un pilar europeo de derechos sociales. Bruselas, 26 de abril de 2017. SWD (2017) 201 final. 
el papel que puede desempeñar el pilar como parte de un sistema del euro más justo ${ }^{45}$. Finalmente, en noviembre de ese mismo año, la Comisión, el Consejo y el PE proclamaron el pilar en el marco de la Cumbre Social de Gotemburgo.

La sistemática del Pilar se estructura en tres capítulos donde se abordan las temáticas de las políticas activas de empleo, la dimensión económica del trabajo, y elementos exógenos a los mercados laborales como son el sinhogarismo, la pobreza y la exclusión social, incorporando un total de veinte principios y derechos ${ }^{46}$. Del conjunto de contenidos podemos extraer las siguientes conclusiones:

45 Documento de trabajo de los servicios de la Comisión: Informe de la consulta pública que acompaña a la Comunicación de la Comisión al Parlamento Europeo, al Consejo, al Comité Económico y Social Europeo y al Comité de las Regiones. Establecimiento de un pilar europeo de derechos sociales. Bruselas 26 de abril de 2017 SWD (2017) 206 final.

46 Capítulo I. Igualdad de oportunidades y de acceso al mercado de trabajo: 1. Derecho a una educación formación y aprendizaje permanente; 2 . Principio de igualdad de género, y derecho a la igualdad de retribución de mujeres y hombres para un trabajo de igual valor; 3 . Derecho a la igualdad de trato y de oportunidades en relación con el empleo, la educación y el acceso a bienes y servicios a disposición del público. 4. Derecho a un apoyo activo para el empleo. Capítulo II. Condiciones de trabajo justas: 5. Derecho a un trato justo y equitativo en materia de condiciones de trabajo y el acceso a la protección social; principio de flexibilidad empresarial, principio de promoción de formas innovadoras de trabajo que garanticen condiciones de trabajo de calidad; principio de prevención del trabajo precario; 6 . Derecho a salarios justos y adecuados para un nivel de vida digno, evitándose la pobreza de los ocupados, y, fijados de manera transparente y predecible. 7. Derecho a ser informado por escrito al comienzo de la relación laboral sobre las condiciones de trabajo y a la protección en caso de despido. 8. Principio de diálogo social y participación de los trabajadores. 9. Derecho a permisos adecuados para conciliar vida profesional y vida privada, y principio de igualdad de acceso de mujeres y hombres a permisos especiales para cumplir con responsabilidades asistenciales. 10. Derecho a un elevado nivel de protección de la salud y seguridad en el trabajo, a un entorno de trabajo adaptado a las necesidades profesionales, y a la protección de datos personales en el contexto del empleo. Capítulo III. Protección e inclusión social: 11. Derecho de los niños a disfrutar de una educación y asistencia asequible y de buena calidad y a la protección contra la pobreza. 12. Derecho a la protección social adecuada de los trabajadores por cuenta ajena y por cuenta propia, en condiciones comparables. 13. Derecho a prestaciones por desempleo de duración razonable y que no desincentiven un retorno rápido al trabajo. 14. Derecho a unas prestaciones de renta mínima. 15. Derecho a recibir una pensión de jubilación. 16. Derecho a un acceso oportuno a asistencia sanitaria. 17. Derecho de las personas con discapacidad a una ayuda a la renta. 18. Derecho a cuidados de larga duración. 19. Principio de acceso a viviendas sociales o ayudas a la vivienda para personas necesitadas; derecho a una asistencia y una protección adecuada frente a un desalojo forzoso; principio de facilitación, a las personas sin hogar, de un alojamiento y servicios adecuados. 
- El Pilar se sitúa en la estrategia de una Europa social de geometría variable forzosa ${ }^{47}$ al concebirse su ámbito de acción en el marco de la zona del euro, lo que cuestiona el carácter potestativo del eslogan «quienes quieren hacer más en el ámbito social, hacen más». Ciertamente, la dimensión social europea requiere para su refuerzo de algo más que un enfoque sectorial circunscrito al marco de la nueva GEE. Profundizar en las carencias de la integración social y tratar de repararlas recurriendo a objetivos sociales de alcance sectorial no parece la medida más eficaz. Por otro lado, el Pilar no contempla las sinergias entre la GEE y el Pilar, sino los beneficios de este último para aumentar la resiliencia y consolidar la Unión Económica y Monetaria (UEM). En particular, cuando se dice en el Considerando 11 que «el progreso económico y social están estrechamente interrelacionados», esta interrelación se concreta en una mejora de la competitividad, como objetivo, a través de la participación en el empleo y la productividad, como medios. La participación en el empleo, a su vez, se concreta en el Capítulo I, 1, en el «derecho a una educación, formación y aprendizaje permanente inclusivos y de calidad, a fin de mantener y adquirir capacidades que les permitan participar en la sociedad y gestionar con éxito las transiciones en el mercado laboral». Una redacción en sintonía con lo dispuesto en el artículo 145 del TFUE: «(...) potenciar una mano de obra cualificada, formada y adaptable y mercados laborales con capacidad de respuesta al cambio económico (...)». Se trata de trasladar la intervención social a la mejora de las condiciones competitivas de los trabajadores o lo que es lo mismo, la protección se alcanza mediante la competitividad. Si descendemos al Capítulo II del Pilar, en ninguna de las disposiciones que lo integran se plantea fijar unos estándares comunes inderogables desde la instancia supranacional en materia de contratación laboral atípica. Todo lo más se habla del deber de evitar relaciones laborales precarias o abusivas sin que se fijen mecanismos de control social a nivel de la zona del euro, o el reconocimiento de un derecho al trabajo con la tutela de su dimensión económica y subjetiva. Probablemente, porque se trata de cuestiones vistas como causas de distorsión de la libre competencia dado que el objetivo social de un empleo seguro y adaptable deberá ser compatible con la garantía de la flexibilidad

${ }^{47}$ Lörcher Klaus e Isabelle Schömann, The European pillar of social rights: critical legal analysis and proposals (Bruselas: European Trade Union Institute, 2017), 30. 
necesaria para que los empresarios puedan adaptarse con rapidez a los cambios en el contexto económico. Esto es, el binomio de la flexiguridad, consistente en fomentar la contratación flexibilizando las garantías tradicionalmente vinculadas a los contratos de trabajo estándares, traslada los derechos laborales al mercado a través de un intercambio de derechos y garantías por un incremento de las oportunidades de empleo. La dinamización del mercado de trabajo pasa por un necesario incremento de la competitividad empresarial que facilitará las posibilidades de acceso al mercado laboral.

- El Pilar ahonda en la divisibilidad de los ficticios derechos sociales europeos ${ }^{48}$ : al distinguir entre derechos y principios reproduce la cuestión de las normas programáticas o de contenidos dependientes de la praxis política-legislativa y el contingente presupuestario. Así, el considerando 14 dispone: "para que los principios y derechos tengan jurídicamente fuerza ejecutiva, es necesario adoptar antes medidas específicas o legislación al nivel adecuado». En este sentido, el Pilar utiliza la retórica de los derechos para perseguir objetivos sociales desvirtuando el propio concepto de derechos sociales. En el gobierno de la economía los derechos sociales representan la dimensión de la tutela económica del trabajo, compensando las incertidumbres del mercado en un sentido solidario. Por el contrario, conforme al modelo normativo y material del constitucionalismo económico europeo, los objetivos sociales no se dirigen a remover los desequilibrios económicosociales que genera el mercado (y, principales detonantes de la desigualdad estructural), sino a fomentar una competencia leal en una economía social de mercado europea.

- El pilar apuesta por una convergencia social de estándares pragmáticos al modelo de una economía de mercado abierta y de libre competencia. El propio Preámbulo reproduce las bases jurídicas que fundamentan los distintos principios y derechos. La reconducción de la política social y de empleo a los principios rectores de saneamiento del euro sistema vuelve a hacer presente la ausencia de una protección adecuada para los modelos del constitucionalismo social frente a los efectos negativos de la integración económica y monetaria. La referencia a la justicia social en el Capítulo III no se conecta a

${ }^{48}$ Christian Joerges, Vladimir Bogoeski y Lukas Nüse, «Economic constitutionalism and the «European Social Model». Can European Law cope with the deepening tensions between economic and social integration after the financial crisis?» (Contribution to the conference «The Metamorphosis of the European Economic Constitution» at theUniversity of Luxembourg, 21-22 September 2017), p. 12. 
la igualdad sustancial, sino a la regulación social indirecta de las directrices del Semestre Europeo. No se establece ningún tipo de sujeción o condicionamiento que constriña el vínculo económico que define el aspecto de garantía y autonomía del mercado único o que genere algún tipo de intervención en sentido corrector. El desfase entre los objetivos reconocidos en el Pilar Europeo y las competencias institucionales de la Unión para materializarlos margina a los objetivos sociales a una situación de inactividad permanente. De este modo, el Pilar representa un indicador significativo de la posición de la dimensión social europea. No se trata de un espacio autónomo que se sitúa al mismo nivel que la integración económica, sino de una mera dimensión de esta última con las características de subordinación y funcionalidad. Por otra parte, el desajuste entre los objetivos sociales y la falta de instrumentos institucionales y de procedimientos decisorios dirigidos a hacerlos operativos en las relaciones intraeuropeas y en los ordenamientos nacionales resulta plenamente coherente con el espacio residual y subalterno que la integración económica reserva a la integración social en el mercado único.

\section{El paquete de equidad social: contenidos propositivos}

El último programa de trabajo de la Comisión ${ }^{49}$, antes de la conclusión de la VIII legislatura, prevé culminar las diez prioridades de la Comisión Juncker inaugurada en 2014. Entre ellas, las dos que han merecido nuestra atención, en cuanto a su vinculación a las políticas sociales y de empleo de la Unión, han sido: «Una Unión Económica y Monetaria más profunda y más justa», donde se sitúa el Pilar Europeo de Derechos Sociales, cuyos objetivos han contribuido, por primera vez, a configurar en el ámbito del Semestre Europeo el proyecto de informe conjunto sobre el empleo y la propuesta de modificación de las orientaciones para el empleo que acompaña al Estudio Prospectivo Anual sobre el Crecimiento de $2018^{50}$. En particular, dentro del apartado, Reformas estructurales para el

${ }^{49}$ Comunicación de la Comisión al Parlamento Europeo, al Consejo, al Comité Económico y Social Europeo y al Comité de las Regiones. Programa de trabajo de la Comisión para 2018. Programa para una Europa más unida, más fuerte y más democrática. Estrasburgo, 24 de octubre de 2017. COM (2017) 650 final.

50 Comunicación de la Comisión. Estudio Prospectivo Anual sobre el Crecimiento 2018. Bruselas, 22 de noviembre de 2017 COM (2017) 690 final. Proyecto de informe conjunto sobre el empleo de la Comisión y el Consejo que acompaña a la Comunicación de la Comisión relativa al Estudio Prospectivo Anual sobre el Crecimiento para 2018. Bruselas, 22 de noviembre de 2017. COM (2017) 674 final. 
crecimiento inclusivo, la convergencia al alza y la competitividad, se contempla un cuadro de treinta y cinco indicadores sociales que contribuyen a examinar los resultados de los EEMM en las esferas social y del empleo a lo largo de las tres dimensiones (capítulos) del pilar y en base a 12 ámbitos $^{51}$. El cuadro de indicadores sociales no se corresponde con los 20 principios del pilar, como pueden ser la estabilidad en el empleo o la protección laboral que no se contemplan. Además, los indicadores separan los componentes propios del concepto trabajo para atomizarlos en torno a la categoría más genérica de personas. Con todo, como apuntábamos, los objetivos del pilar se insertan en el proceso de fragmentación y remercantilización-individualización de los derechos que exige el abandono de la subjetivización del trabajo. De ahí la operatividad del pilar a la integración económica.

Centrándonos en la segunda de las prioridades, «Un mercado interior más justo y profundo, con una base industrial fortalecida», se contextualizan las propuestas de reforzar y garantizar la movilidad laboral y de modernizar la coordinación de los sistemas de seguridad social nacionales. La primera ha culminado en la adopción, en 2018, de la Directiva renovada sobre trabajadores desplazados para la prestación de servicios; mientras que la segunda, aún está en fase de negociación entre el Consejo y el Parlamento. Aunque estas acciones han sido abordadas pormenorizadamente en el segundo apartado, el programa para 2018 articula una nueva iniciativa directamente relacionada con los retos de la movilidad y la coordinación, como es la creación de una Autoridad Laboral Europea $(\mathrm{ALE})^{52}$ perfilada con mayor detalle en el nuevo «paquete de equidad social» presentado el 13 de marzo de $2018^{53}$. La propuesta de Reglamento del PE y del Consejo por el que se crea la $\mathrm{ALE}^{54}$ señala como objetivos

51 Dentro del Capítulo I del Pilar, se establecen los siguientes cinco ámbitos: Educación, capacidades y aprendizaje permanente; Igualdad de género en el mercado de trabajo; Desigualdad de ingresos; Tasa de riesgo de pobreza o de exclusión social; Juventud. Dentro del Capítulo II, los ámbitos que se reconocen son: Estructura de la población activa (tasa de empleo y de desempleo); Políticas del mercado de trabajo; Ingresos y salarios. Finalmente, como ámbitos del Capítulo III: Impacto de las políticas públicas en la reducción de la pobreza. Educación y atención a la primera infancia; Asistencia sanitaria; Acceso al mundo digital y capacidades digitales.

52 COM (2017) 650 final, p.6.

53 Comunicación de la Comisión al Parlamento Europeo, al Consejo y al Comité Económico y Social Europeo. Supervisión de la aplicación del pilar europeo de derechos sociales. Estrasburgo, 13 de marzo de 2018. COM (2018) 130 final. Previamente, en el Anexo que acompañaba la Comunicación de la Comisión Europea sobre el programa de trabajo para 2018, la iniciativa n. $^{\circ} 8$, se pergeñaba el contenido básico del futuro paquete de equidad social: https://ec.europa.eu/info/sites/info/files/file_import/cwp_2018_annex_i_es.PDF, acceso el 12 de diciembre de 2018, p. 4.

${ }^{54}$ Estrasburgo, 13 de marzo de 2018. COM (2018) 131 final. 
prioritarios de la agencia descentralizada: «mejorar el acceso de las personas y los empleadores a la información sobre sus derechos y obligaciones en los ámbitos de la movilidad laboral y la coordinación de la seguridad social, así como el acceso a los servicios pertinentes; reforzar la cooperación operativa entre las autoridades en la aplicación transfronteriza de la legislación de la Unión pertinente, incluida la facilitación de inspecciones conjuntas; proporcionar mediación y facilitar las soluciones en casos de diferencias entre autoridades nacionales y de perturbaciones del mercado laboral transfronterizo, tales como las reestructuraciones de empresas que afectan a varios EEMM» (páginas 3 y 4 de la propuesta de Reglamento). El ámbito subjetivo sería, por ende, la ciudadanía móvil por cuenta propia y por cuenta ajena, y las empresas transfronterizas. Nuevamente, se rehúye el uso de la categoría trabajadores. Las causas de la iniciativa hay que localizarlas en las insuficiencias de los mecanismos existentes en el espacio europeo para combatir, prevenir y detectar el fraude social transfronterizo, ámbito material de actuación de las disposiciones de la propuesta reglamentaria. En esta línea, el Sistema de Información del Mercado Interior (IMI) ${ }^{55}$ carece de operatividad efectiva limitándose a facilitar el intercambio de flujos de información entre EEMM de origen y acogida de los trabajadores desplazados, esto es, cooperación administrativa, sin que la solicitud implique activar directamente una inspección o se contemplen mecanismos de detección de posibles fraudes transfronterizos. Asimismo, la Plataforma europea para reforzar la cooperación en materia de lucha contra el trabajo no declarado también carece de las facultades necesarias para afrontar el fraude transfronterizo al limitarse a funcionar como un mecanismo de intercambio de buenas prácticas e información, y de análisis de la legislación nacional y europea para combatir el trabajo no declarado a escala interna y transfronteriza ${ }^{56}$. Para valorar si la ALE supone un salto cualitativo con relación a los instrumentos señalados, resulta de interés descender al tenor del articulado relativo a las funciones de cooperación e intercambio de información entre EEMM, así como a la actuación frente a los riesgos de la movilidad laboral transfronteriza. Con respecto a la primera de las funciones, no se contempla ninguna con-

55 Reglamento (UE) No 1024/2012 del Parlamento Europeo y del Consejo de 25 de octubre de 2012 relativo a la cooperación administrativa a través del Sistema de Información del Mercado Interior y por el que se deroga la Decisión 2008/49/CE de la Comisión («Reglamento IMI»). Diario Oficial de la Unión Europea, 14 de noviembre de 2012, L 136/1-136/11.

56 Decisión (UE) 2016/344 del Parlamento Europeo y del Consejo de 9 de marzo de 2016 relativa a la creación de una Plataforma europea para reforzar la cooperación en materia de lucha contra el trabajo no declarado. Diario Oficial de la Unión Europea, 11 de marzo de 2016, L 65/12-65/20. 
secuencia jurídica ante la negativa de un Estado miembro a participar en las inspecciones conjuntas o concertadas (artículo 9.257). En la segunda, las labores se limitan a medidas de tipo soft, recomendaciones, sin que se prevea la capacidad de imposición de sanciones (artículo 11 ${ }^{58}$ ). Aspectos que cuestionan la novedad de las funciones. Por último, el 6 de diciembre de 2018, el Consejo ha acordado su posición negociadora sobre la creación de una ALE, proponiendo un cambio de denominación de «Autoridad Laboral Europea» a «Agencia Laboral Europea». En estos momentos, está pendiente el inicio de las negociaciones con el Parlamento.

Con relación a la segunda de las iniciativas del paquete de equidad social, la Comisión propone una Recomendación del Consejo sobre el acceso a la protección social de los trabajadores por cuenta ajena y por cuenta propia ${ }^{59}$ para paliar los efectos negativos generados por la globalización y las nuevas tecnologías en los mercados de trabajo nacionales. Concretamente, eliminar o reducir los obstáculos que impiden a esta tipología de trabajadores acceder a los sistemas de protección social corres-

57 «Cuando la autoridad de un Estado miembro decida no participar en la inspección concertada o conjunta mencionada en el apartado 1 o no llevarla a cabo, informará a la Autoridad por escrito con suficiente antelación sobre las razones de su decisión. En tales casos, la Autoridad informará a las demás autoridades nacionales afectadas».

58 «Análisis y evaluación de riesgos de la movilidad laboral transfronteriza. 1. La Autoridad evaluará los riesgos y realizará análisis de los flujos laborales transfronterizos, tales como los desequilibrios del mercado laboral, las amenazas sectoriales y los problemas recurrentes encontrados por las personas y los empleadores en relación con la movilidad transfronteriza. A tal efecto, la Autoridad garantizará la complementariedad con la experiencia de otras agencias o servicios de la Unión, y se basará en ella, incluso en los ámbitos de la previsión de capacidades y de la salud y la seguridad en el trabajo. A petición de la Comisión, la Autoridad podrá realizar análisis y estudios en profundidad para investigar cuestiones específicas de la movilidad laboral. 2. La Autoridad organizará revisiones inter pares entre las autoridades y los servicios nacionales a fin de: a) examinar las cuestiones, las dificultades y los problemas específicos que puedan surgir en relación con la implementación y aplicación práctica de la legislación de la Unión en el ámbito de las competencias de la Autoridad, así como con su cumplimiento en la práctica; b) reforzar la coherencia de la prestación de servicios a las personas y los empleadores; c) mejorar el conocimiento y la comprensión mutua de los diferentes sistemas y prácticas, así como evaluar la eficacia de las diferentes medidas políticas, incluidas las medidas de prevención y disuasión. 3. La Autoridad informará periódicamente sobre sus constataciones a la Comisión, así como directamente a los Estados miembros en cuestión, indicando posibles medidas para abordar las deficiencias detectadas. 4. La Autoridad reunirá los datos estadísticos recopilados y presentados por los Estados miembros en los ámbitos de la legislación de la Unión que son competencia de la Autoridad. Al hacerlo, la Autoridad intentará racionalizar las actividades actuales de recogida de datos en dichos ámbitos. Cuando proceda, se aplicará el artículo 16. La Autoridad será el punto de enlace con la Comisión (Eurostat) y compartirá, en su caso, los resultados de sus actividades de recogida de datos».

${ }^{59}$ Estrasburgo, 13 de marzo de 2018. COM (2018) 132 final. 
pondientes de forma tal que puedan acumular y hacer valer derechos adecuados como miembros de un régimen (artículos 12 a 15 de la propuesta); garantizar la transferibilidad de los derechos entre los diferentes regímenes y su totalización (artículo 11 de la propuesta); e incrementar la transparencia de las condiciones laborales y de la normativa de los regímenes sociales (artículos 16 y 17 de la propuesta). Sin embargo, quedan excluidas del ámbito de aplicación de la recomendación cuestiones cruciales para perseguir la finalidad a la que se dirige. Por citar algunas de ellas: no se garantiza la obligatoriedad de las prestaciones por desempleo para los trabajadores por cuenta propia, aspecto relevante si consideramos el fenómeno al alza de los falsos autónomos; y el nivel de protección, en su vertiente de cobertura obligatoria o voluntaria, es discrecional para los EEMM.

Finalmente, resta por hacer mención a la propuesta de revisión de la Directiva sobre la obligación de informar por escrito ${ }^{60}$ como iniciativa legislativa vinculada al programa de trabajo para 2018. Al igual que en la propuesta de Recomendación, las referencias a unos mercados de trabajo en continua transformación generando nuevas formas de empleo, básicamente, no convencionales requiere un marco de condiciones laborales mejorado que de mayor transparencia a las normativas laborales internas, sin obstaculizar la competitividad empresarial, y que permita conjugar en una relación equilibrada la flexibilidad propia de las contrataciones laborales atípicas con la seguridad de las relaciones estándares. Entre las modificaciones más significativas destacan: la exclusión de la aplicación del artículo 1.3 de la Directiva solo a las relaciones laborales de menos de ocho horas al mes, lo que permitiría incluir nuevas formas de trabajo que con la actual redacción quedan fuera (trabajo doméstico, trabajo intermitente); el establecimiento de una definición de trabajador de acuerdo con la jurisprudencia del TJUE. En particular, las características cumulativas de dependencia, remuneración y actividad económica real y efectiva. Por otro lado, en el artículo 3 se introducen nuevos requisitos mínimos de información, considerando las especificidades de las plataformas en línea o el procedimiento de terminación del empleo. Además, conforme a la nueva redacción del artículo 4 se reduce el plazo de entrega de la información de 2 meses al primer día de la relación laboral; y, en lo que concierne a la duración del periodo de prueba, se establece una duración máxima para todos los periodos de prueba de 6 meses. Por último, se introducen, entre otros, nuevos derechos materia-

60 Propuesta de Directiva del Parlamento Europeo y del Consejo relativa a unas condiciones laborales transparentes y previsibles en la Unión Europea. Bruselas, 21 de diciembre de 2017, COM (2017) 797 final. 
les como la prohibición de las cláusulas de exclusividad (artículo $8^{61}$ ) o la previsibilidad mínima del trabajo (artículo ${ }^{62}$ ).

El elenco de iniciativas legislativas y no legislativas descritas se sitúa en el contexto de la nueva dimensión social para Europa a la que apela el Pilar. En ellas se citan expresamente los capítulos y objetivos sociales que fundamentan las nuevas redacciones. Pero, el propio alcance programático del pilar se traslada al grueso propositivo descrito.

\section{Conclusiones}

A lo largo de esta reflexión hemos tratado de reflejar las características comunes a las distintas iniciativas impulsadas por la Comisión para construir la integración social europea del futuro, siguiendo la Agenda de prioridades trazada por Juncker en 2014, para valorar si estas suponen cambios o modificaciones sustanciales que materialicen un punto de inflexión con la actual integración positiva. En este sentido, las referencias a la génesis y evolución de la integración social, consustancial a las diferentes normativas de derecho originario y derivado que han acompañado el proceso de integración, son obligatorias. Trazada la comparativa entre ambas procede señalar un doble orden de consideraciones. En primer lugar, no podemos hablar de ruptura, siquiera de reforma, en el proceso de construcción, avance y revisión/renovación de la dimensión social europea, sino de reafirmación de los principios estructurales originarios del modelo social europeo. Un modelo que, como hemos reiterado, se contrapone al del constitucionalismo democrático social, de ahí que el enfoque sea radicalmente distinto.

En segundo lugar, y como consecuencia directa, el ordenamiento supranacional europeo establece una composición de relación entre las di-

61 «Empleo en paralelo. 1. Los Estados miembros velarán por que un empleador no prohíba a los trabajadores aceptar empleos con otros empleadores fuera del calendario de trabajo establecido con dicho empleador. 2. No obstante, los empleadores podrán fijar las condiciones de incompatibilidad cuando estas restricciones estén justificadas por motivos legítimos tales como la protección del secreto empresarial o la prevención de conflictos de interés».

62 «Si el calendario de trabajo de un trabajador es total o fundamentalmente variable y está total o fundamentalmente determinado por el empleador, los Estados miembros velarán porque el empleador pueda exigir al trabajador que realice sus tareas únicamente si: a)las tareas tienen lugar en unas horas y unos días de referencia predeterminados, establecidos por escrito al comienzo de la relación laboral, de conformidad con el artículo 3, apartado 2, letra 1), inciso i), y b) si el empleador informa al trabajador de una tarea asignada con suficiente antelación, de conformidad con el artículo 3, apartado 2, letra 1), inciso ii)». 
mensiones positiva y negativa donde los componentes sociales y económicos se conjugan desde la disciplina de la integración económica condicionante y de la integración social condicionada. En los programas de trabajo de 2016, 2017 y 2018, se reconoce el alma económica de la integración positiva que no se configura como espacio de contención de los desequilibrios materiales del mercado sino como funcional a las instancias productivas. Paralelamente, se aprecia la dimensión extraeconómica de la propia integración económica recurriendo a las técnicas de la regulación social indirecta, consistentes en modificaciones en la redacción de la legislación sobre coordinación de los sistemas de seguridad social, condiciones de trabajo, y trabajadores transfronterizos en base a la prevención, detección y control de la competencia desleal entre operadores económicos. Sobre esta base valorativa es posible comprender los motivos de las complejas interacciones entre los dos sistemas normativos.

El compromiso social de la integración económica resume los contornos más significativos de la perspectiva evolutiva en la integración económica que ya no se limita a garantizar la maximización de la eficiencia de la libre competencia, sino también, en palabras de los documentos de trabajo, a promover y realizar el bienestar social supranacional. La dimensión plural de la dimensión social y la dimensión económica se reconduce a un compromiso entre la competición económica y el bienestar de la colectividad. Esta estrategia supone excluir una aproximación al mercado único y sus correlatos en sentido neoliberal y, al mismo tiempo, una aproximación a la integración positiva desde una dimensión exclusivamente social. La introducción en el ámbito de aplicación de la disciplina del mercado único (y, especialmente, de la UEM, por lo que respecta a los objetivos sociales del pilar) de iniciativas de un aparente reequilibrio social en las políticas de regulación del mercado es paralela a unas propuestas de modernización del acquis social comunitario que exhiben su funcionalidad al crecimiento y desarrollo de los sistemas socio-económicos. Los presuntos componentes ambivalentes de sendas dimensiones explosionan su virtuosismo en el escenario del mercado único bajo el mantra de que el fortalecimiento del mercado único genera progreso social y de que los niveles de bienestar social elevados y equiparables entre los EEMM son un componente vital de la integración económica. Circunstancia que lleva a la Comisión Europea a asumir una perspectiva de extensión o generalización de las contaminaciones virtuosas entre integración económica y objetivos sociales. 


\section{Bibliografía}

Barnard, Catherine. «Viking and Laval: An Introduction». Cambridge Yearbook of European Legal Studies (2008): 463-492. https://doi.org/10.1017/ S1528887000001403.

European Trade Union Confederation, «Reflection Paper on the Social Dimension of Europe». ETUC Assessment (position). Adopted at the ETUC Executive Committee on 13-14 June 2017, 1-8.

Goetschy, Janine. «The European Employment Strategy: genesis and development». European Journal of Industrial Relations, n. ${ }^{\circ} 2$ (1999): 117-137. https://doi. org/10.1177/095968019952002.

Gutiérrez-Peris, Dídac. «New Realignment of Fears in France and Europe». Cuadernos Europeos de Deusto, n. 59 (2018): 99-114. doi: http://dx.doi. org/10.18543/ced-59-2018, 99-114.

Innerarity Grau, Daniel. «La representación de los europeos: sobre la posibilidades y límites de la parlamentarización de la Unión Europea». Cuadernos Europeos de Deusto, n. 56 (2017): 163-179. doi: http://dx.doi.org/10.18543/ced-56-2017.

Joerges, Christian, Vladimir Bogoeski y Lukas Nüse. «Economic constitutionalism and the «European Social Model». Can European Law cope with the deepening tensions between economic and social integration after the financial crisis?».Contribution to the conference «The Metamorphosis of the European Economic Constitution» at theUniversity of Luxembourg, 21-22 September 2017, 1-22.

Juncker, Jean-Claude. «Un nuevo comienzo para Europa: mi Agenda en materia de empleo, crecimiento, equidad y cambio democrático». Estrasburgo, 15 de julio de 2014. Acceso el 10 de diciembre de 2018. http://europa.eu/rapid/pressrelease_SPEECH-14-546_es.htm, acceso el 10 de diciembre de 2018.

Kenner, Jeff. «Employment and macroeconomics in the EC Treaty: a legal and political symbiosis?». Maastricht journal of European and comparative law, n. 4 (2000): 375-397. https://doi.org/10.1177/1023263X0000700404.

Kilpatrick, Claire. «The displacement of Social Europe: a productive lens of inquiry». European Constitutional Law Review, n. ${ }^{\circ} 1$ (2018): 62-74. https://doi. org/10.1017/S1574019618000019.

Klaus Lörcher e Isabelle Schömann. The European pillar of social rights: critical legal analysis and proposals. Bruselas: European Trade Union Institute, 2017.

Lasa López, Ainhoa. «Constitución económica europea y modelo social: límites e ineficiencias de la integración negativa mejorada en la lucha contra la exclusión social». Cuadernos Europeos de Deusto, n. 53 (2015): 133-165.

Lirola Delgado, Isabel. «Derecho de residencia de los ciudadanos de la Unión y prestaciones sociales en tiempos de crisis: ¿Hacia un planteamiento casuístico y ambiguo de la solidaridad entre los Estados miembros?». Revista de Derecho Comunitario Europeo, n. 49 (2015): 733-766.

- «La sentencia Dano: ¿El punto final de los «malabarismos del TJUE en materia de libre circulación de los ciudadanos de la Unión inactivos económicamente?». Revista General de Derecho Europeo, n. ${ }^{\circ} 36$ (2015): 1-27. 
Muir, Elise. «Drawing positive lessons from the presence of "The Social" Outside of EU Social Policy stricto sensu». European Constitutional Law Review, n. ${ }^{\circ} 1$ (2018): 75-95. https://doi.org/10.1017/S1574019618000020.

Sciarra, Silvana. "Viking and Laval: Collective Labour Rights and Market Freedoms in the Enlarged EU». Cambridge Yearbook of European Legal Studies (2008): 563-580. https://doi.org/10.1017/S1528887000001440.

Schiek, Dagmar. «Perspectives on social citizenship in the EU: from status positivus to status socialis activus via two forms of transnational solidarity». En EU Citizenship and Federalism. The Role of Rights, editado por Dimitry Kochenov, 341-370. Cambridge University Press, 2017.

Standing, Guy. The precariat. The new dangerous class. London: Bloomsbury Academic, 2011.

Trubek, David M. y Trubek, Louise G. «Hard and soft law in the construction of social europe: the role of the open method of co-ordination». European Law Journal, n. 3 (2005): pp. 351-356. https://doi.org/10.1111/j.14680386.2005.00263.x.

\section{Sobre la autora}

Ainhoa Lasa López es profesora ayudante doctora de Derecho Constitucional en la Universidad de Alicante. Sus principales líneas de investigación son: poder global de mercado, constitución económica europea, derechos sociales, y distribución territorial del poder en el marco del constitucionalismo de mercado europeo. Es autora de dos monografías: «Los derechos sociales en el constitucionalismo de mercado: aporías de la dimensión social en la Unión Europea», 2012, edit. Servicio de Publicaciones de la Universidad del País Vasco, UPV/EHU. Y, «Constitución económica y derecho al trabajo en la Unión Europea», 2011, edit. Comares. Entre sus publicaciones más recientes se encuentran: «Autonomía del Derecho Constitucional de la Unión y mecanismo de resolución de controversias entre inversores y estados ¿maridaje o disonancia?: reflexiones sobre el Asunto C-284/16 Slowakische Republik y Achmea BV», Unión Europea Aranzadi, n. ${ }^{\circ}$ 11, 2018. «Potencialidades del Pilar Europeo de Derechos Sociales en la praxis jurisprudencial del Juez de Estrasburgo: entre la heterarquía vínculo social-vínculo económico y la disfuncionalidad», Teoría y Realidad Constitucional, n. ${ }^{\circ}$ 42, 2018. «La narrativa de la Europa social en la historia del proceso de integración: de la solidaridad competitiva a la necesaria justicia redistributiva», en JOXERRAMON/ BENGOETXEA, «Nuevas narrativas para Europa: ¿qué Europa reconstruir tras 60 años de los Tratados de Roma?», Madrid, 2018, edit. Dykinson, pp. 205-222. 


\section{About the Author}

Ainhoa Lasa López is a lecturer on Constitutional Law at the University of Alicante. Her main lines of research are: global market power, European economic constitution, social rights, and territorial distribution of power within the framework of European market constitutionalism. She has published two books: «Los derechos sociales en el constitucionalismo de mercado: aporías de la dimensión social en la Unión Europea», 2012, edit. Servicio de Publicaciones de la Universidad del País Vasco, UPV/EHU. And «Constitución económica y derecho al trabajo en la Unión Europea», 2011, edit. Comares. Among the most recent publications are: «Autonomía del Derecho Constitucional de la Unión y mecanismo de resolución de controversias entre inversores y estados ¿maridaje o disonancia?: reflexiones sobre el Asunto C-284/16 Slowakische Republik y Achmea BV», Unión Europea Aranzadi, n. ${ }^{\circ}$ 11, 2018. «Potencialidades del Pilar Europeo de Derechos Sociales en la praxis jurisprudencial del Juez de Estrasburgo: entre la heterarquía vínculo social-vínculo económico y la disfuncionalidad», Teoría y Realidad Constitucional, n. $^{\circ} 42,2018$. «La narrativa de la Europa social en la historia del proceso de integración: de la solidaridad competitiva a la necesaria justicia redistributiva», en JOXERRAMON/BENGOETXEA, «Nuevas narrativas para Europa: ¿qué Europa reconstruir tras 60 años de los Tratados de Roma?», Madrid, 2018, edit. Dykinson, pp. 205-222. 


\section{Derechos de autor}

Los derechos de autor (para la distribución, comunicación pública, reproducción e inclusión en bases de datos de indexación y repositorios institucionales) de esta publicación (Cuadernos Europeos de Deusto, CED) pertenecen a la editorial Universidad de Deusto. El acceso al contenido digital de cualquier número de Cuadernos Europeos de Deusto es gratuito inmediatamente después de su publicación. Los trabajos podrán leerse, descargarse, copiar y difundir en cualquier medio sin fines comerciales y según lo previsto por la ley; sin la previa autorización de la Editorial (Universidad de Deusto) o el autor. Así mismo, los trabajos editados en CED pueden ser publicados con posterioridad en otros medios o revistas, siempre que el autor indique con claridad y en la primera nota a pie de página que el trabajo se publicó por primera vez en CED, con indicación del número, año, páginas y DOI (si procede). Cualquier otro uso de su contenido en cualquier medio o formato, ahora conocido o desarrollado en el futuro, requiere el permiso previo por escrito del titular de los derechos de autor.

\section{Copyright}

Copyright (for distribution, public communication, reproduction and inclusion in indexation databases and institutional repositories) of this publication (Cuadernos Europeos de Deusto, CED) belongs to the publisher University of Deusto. Access to the digital content of any Issue of Cuadernos Europeos de Deusto is free upon its publication. The content can be read, downloaded, copied, and distributed freely in any medium only for non-commercial purposes and in accordance with any applicable copyright legislation, without prior permission from the copyright holder (University of Deusto) or the author. Thus, the content of CED can be subsequently published in other media or journals, as long as the author clearly indicates in the first footnote that the work was published in CED for the first time, indicating the Issue number, year, pages, and DOI (if applicable). Any other use of its content in any medium or format, now known or developed in the future, requires prior written permission of the copyright holder. 